\title{
Natural Selection and the Evolution of Life Expectancy *
}

\author{
Oded Galor and Omer Moav ${ }^{\dagger}$
}

August 24, 2004

\begin{abstract}
This research develops an evolutionary growth theory that captures the intricate time path of life expectancy in the process of development, shedding new light on the origin of the remarkable rise in life expectancy since the Agricultural Revolution. The theory argues that social, economic and environmental changes that were associated with the transition from hunter-gatherer tribes to sedentary agricultural communities and ultimately to urban societies affected the nature of the environmental hazards confronted by the human population, triggering an evolutionary process that had a significant impact on the time path of human longevity.
\end{abstract}

Keywords: Life Expectancy, Growth, Technological Progress, Evolution, Natural Selection, Malthusian Stagnation.

JEL classification Numbers: I12, J13, N3, O10.

${ }^{*}$ The authors wish to thank Roland Benabou, Herbert Ginitis, Moshe Hazan, Peter Howitt, David Laibson, Rodrigo Soares, and David Weil, for helpful discussion and comments, and Tamar Roth for excellent research assistantship.

${ }^{\dagger}$ Galor: Hebrew University and Brown University; Moav: Hebrew University; 


\section{Introduction}

This research develops an evolutionary growth theory that captures the intricate time path of life expectancy in the process of development, shedding new light on the origin of the remarkable rise in life expectancy since the Agricultural Revolution. The theory argues that social, economic and environmental changes that were associated with the transition from hunter-gatherer tribes to sedentary agricultural communities and ultimately to urban societies affected the nature of the environmental hazards confronted by the human population, triggering an evolutionary process that had a significant impact on the time path of human longevity. The theory suggests that the deterioration in the health environment enhanced the genetic potential for longer life expectancy thereby playing a significant role in the dramatic impact of recent improvements in health infrastructure on the prolongation of human life.

The rise in population density, the domestication of animals, and the increase in work effort in the course of the Agricultural Revolution increased the exposure and the vulnerability of humans to environmental hazards such as infectious diseases and parasites, increasing the extrinsic mortality risk and leading to the observed temporary decline in life expectancy during the Neolithic period, as depicted in Figure 1 and detailed in Table $1 .^{1}$ The theory suggests, however, that in light of the implicit aspiration of humans, as well as other species, to maximize the number of their surviving offspring, the evolutionary optimal allocation of parental resources towards somatic investment, repairs, and maintenance (e.g., enhanced immune system, DNA repairs, accurate gene regulation, tumor suppression, and antioxidants) was altered in the face of the fundamental trade-off between current and future reproduction. The rise in the extrinsic morality risk generated an evolutionary advantage to individuals who were genetically pre-disposed towards higher somatic investment leading to the observed increase in life expectancy in the post-Neolithic period, as depicted in Figure $1 .^{2}$

\footnotetext{
${ }^{1}$ Most comparisons between hunter-gatherers and farmers (e.g., Cohen (1989)) suggest that, in the same locale, farmers suffered higher rates of infection due to the increase in human settlements in size and permanence, poorer nutrition due to reduced meat intake and greater interference with mineral absorption by the cereal-based diet. Consequently, Neolithic farmers were shorter and had a lower life expectancy relative to Mesolithic hunter-gatherers. Although it is difficult to draw reliable conclusion about relative life expectancy in these periods, because skeletal samples are often distorted and incomplete, available evidence suggests that prehistoric hunter-gatherers often fared relatively well in comparison to later populations, particularly with reference to the survival of children. The Illinois Valley provides life tables for hunter-gatherers which confirm the fact that their life expectancies matched or exceeded those of later groups. Additional evidence mostly from the Old World, are provided in Table 1, and are depicted in Figure 1.

${ }^{2}$ As argued by Angel (1984), partial recoveries from the major breakdown of human health during the transition from hunting to farming, occurred during the Bronze Age.
} 
The proposed theory suggests, therefore, that the increase in the extrinsic morality risk (i.e., risk associated with environmental factors) in the course of the Agricultural Revolution triggered an evolutionary process that gradually altered the distribution of genes in the human population that are associated with the intrinsic mortality risk (i.e., physiological and biochemistry decay over lifetime). Individuals that were characterized by a higher genetic predisposition towards somatic investment, repairs, and maintenance gained the evolutionary advantage during this transition, and their representation in the population increased over time. ${ }^{3}$ Despite the increase in the extrinsic mortality risk that brought about a temporary decline in life expectancy, longevity eventually increased beyond the peak that existed in the hunter-gatherer society, due to the changes in the distribution of genes in the human population. Moreover, the biological upper bound of longevity gradually increased, generating the biological infrastructure that contributed significantly to the impact of recent improvements in medical technology on the dramatic prolongation of life expectancy.

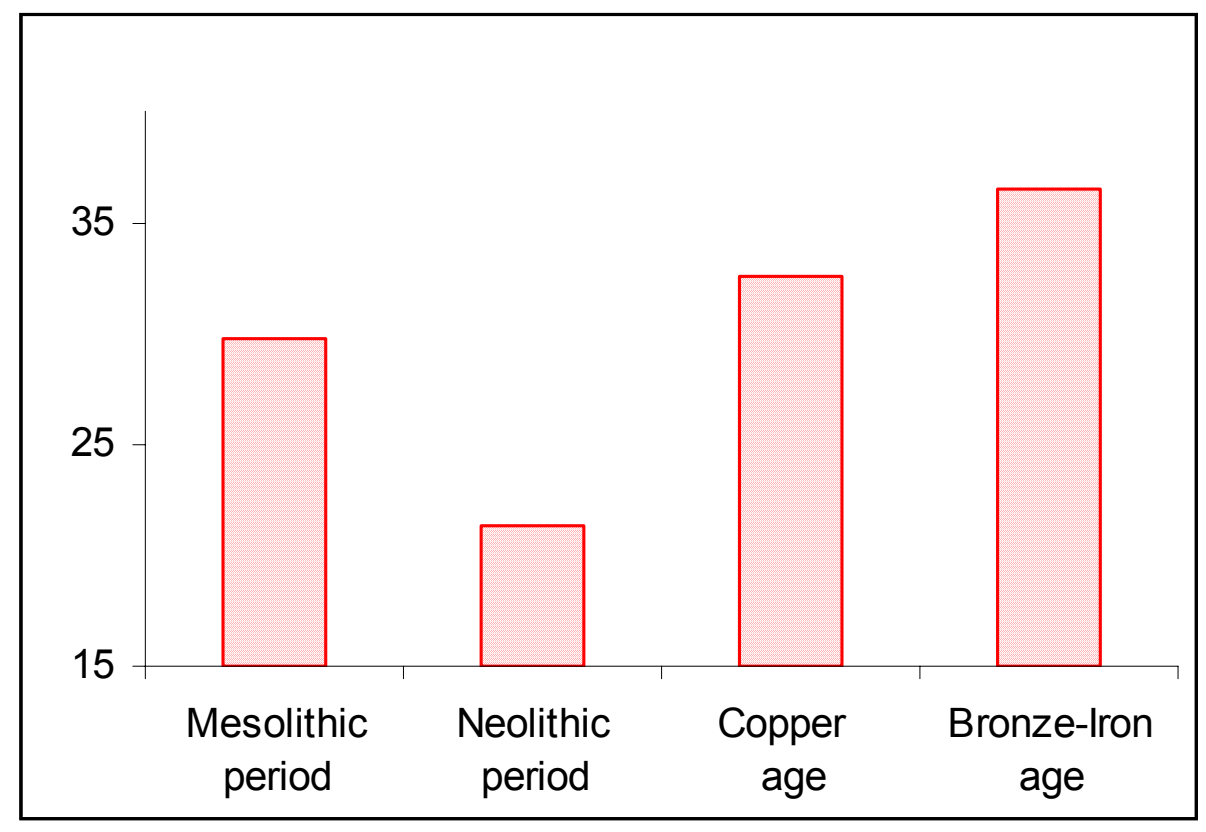

Figure 1: The Non-Monotonic Evolution of Life Expectancy (at birth) in the course of the Agricultural Revolution

The evolutionary process that was triggered by the transition to sedentary agriculture was reinforced by the gradual rise in the extrinsic mortality risk that accompanied the process of de-

\footnotetext{
${ }^{3}$ For the effect of somatic maintenance system on longevity see Kirkwood (1998).
} 
velopment since the Agricultural Revolution, prior to the improvements in health infrastructure. The gradual increase in population size and thereby population density, stemming from the effects of division of labor, trade, and technological progress in a Malthusian environment, generated an additional increase in the extrinsic mortality risk, further elevating the evolutionarily optimal level of resources that were devoted to somatic investment, repairs, and maintenance. Eventually, this enhancement in the evolutionary process further increased the survival probability and the biological upper bound of longevity, contributing to the prolongation of life expectancy. ${ }^{4}$

The process of urbanization and the associated rise in the concentration of the population further contributed to the increase in the extrinsic mortality risk. It brought about a temporary decline in life expectancy along with a reinforcement of the existing evolutionary pressure, enhancing the trend of rising life expectancy. ${ }^{5}$ During the initial process of European urbanization in which the percentage of the urban population increased six-fold from about 3\% in 1520 to nearly 18\% in 1750 [de Vries (1984) and Bairoch (1988)], the rapid increase in population density generated a rise in mortality rates and a decline in life expectancy. ${ }^{6}$ As depicted in Figure 2, life expectancy at birth fell from about 40 at the end of the 16th century to about 33 in the beginning of the 17th century while mortality rates increased by nearly $50 \%$ (Wrigley and Schofield, 1981). However, the theory asserts that the evolutionary process, that increased the representation of individuals who were genetically pre-disposed towards higher somatic investment, was enhanced by this additional rise in the extrinsic mortality risk, contributing to the observed rise in life expectancy in the 18th and the first half of the 19th centuries. A decline in mortality along with a rise in life expectancy began in the beginning of the 17th century and life expectancy at birth rose from about 33 to above 40 in England until the middle of the 19th century, prior to significant advancements in medical technologies. [Livi-Bacci (1997)]. ${ }^{7}$

\footnotetext{
${ }^{4}$ The eventual trend of increasing life expectancy was accompanied by regional fluctuations, reflecting local environmental and climatic conditions. For instance, life expectancy fluctuated in the Malthusian epoch, ranging from 24 in Egypt in the time period 33 - 258 AD, to 42 in England in the end 16th century.

${ }^{5}$ Major epidemics such as the Black Death in Europe in the middle of the 14th century, further contributed to the increase in the extrinsic mortality risk (e.g., McNeil (1998)) bringing about an initial decline in life expectancy, and potentially enhancing the evolutionary process associated with the trend of increased life expectancy.

${ }^{6}$ Consistently with the hypothesis that the rise in mortality rate was associated with increased urbanization Clark and Hamilton (2003) find that in England during the early part of the 17th century, the average number of surviving offspring was nearly $50 \%$ higher among rural families in comparison to urban families, controlling for literacy. Furthermore, it should be noted that the evolutionary pressure in the urban environment was probably severe due to high infant mortality rates. For instance, in the early 19th century infant mortality rate in London was in access of 400 per 1000 (Laxton and Williams, 1989), whereas infant mortality in the population as a whole was 104 per 1000 in the first half of the 18th century and 49 per 1000 in time interval 1825-1837. (Wrigley and Schofield, 1981).

${ }^{7}$ As argued by Mokyr (1998), significant improvements in health infrastructure did not occur prior to the middle
} 


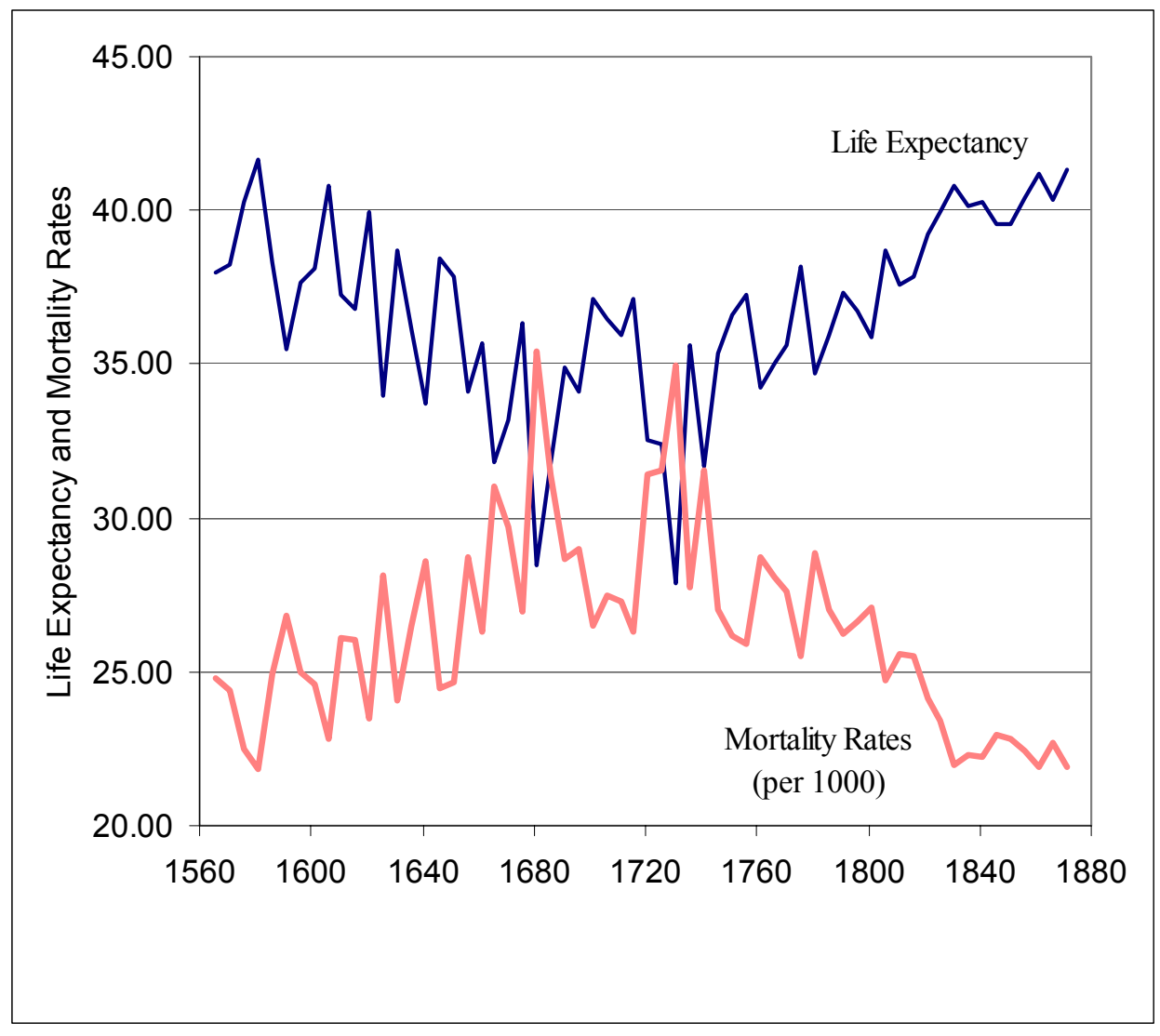

Figure 2: The Non-Monotonic Time Path of Mortality Rates and Life Expectancy (at birth) in the Course of Early Urbanization: England 1540-1870. (Source: Wrigley and Schofield (1981))

The theory predicts that the interaction between the rise in the extrinsic mortality risk and the evolutionary process manifests itself in the observed non-monotonic time path of life expectancy, provided that the rise in the mortality risk is sufficiently rapid. In the short run - while the composition of the population remains nearly stationary - the rise in the mortality risk reduces life expectancy. However, the evolutionary process triggered by the environmental change and enhanced by the endogenous process of increased population density gives rise to an advantage for individuals characterized by higher life expectancy and higher biological upper bound of longevity, increasing their representation in the population. As the composition of the population shifts sufficiently in favor of individuals with higher life expectancy, the population's life expectancy increases and ultimately it might be higher than the level that existed prior to the increase in the mortality risk. Moreover, the rise in the extrinsic mortality risk increases the gap of the 19 th century. 
between the biological upper bound of longevity and life expectancy, generating the biological infrastructure for a dramatic effect of rapid improvements in health infrastructure and medical technology (and the associated reduction in the extrinsic mortality risk), on the prolongation of life expectancy.

Consistent with the proposed theory, evidence suggest that changes in the environment may generate rapid evolutionary processes in the composition of existing genetic traits. In particular, the time period between the Agricultural Revolution and the Industrial Revolution that lasted about 10,000 years is sufficient for significant evolutionary changes in the human population. There are numerous examples of rapid evolutionary changes among various species that were triggered by significant changes in the environment. ${ }^{8}$ In particular, evidence establishes that the change in the environment during the Agricultural Revolution generated rapid evolutionary changes in the human population. For instance, lactose tolerance was developed among European and Near Easterners since the domestication of dairy animals in the course of the Agricultural Revolution, whereas in regions that were exposed to dairy animals in later stages a larger proportion of the adult population suffers from lactose intolerance. Furthermore, genetic immunity to malaria provided by the sickle cell trait is prevalent among descendents of Africans whose engagement in agriculture improved the breeding ground for mosquitoes and thereby raised the incidence of malaria, whereas this trait is absent among descendents of nearby populations that have not made the transition to agriculture. ${ }^{9}$

The theory explores the evolution of the distribution of life-history profiles (i.e., the life cycle of somatic investment and its effect on life expectancy $)^{10}$ in light of the fundamental tradeoff that exist in nature between investments in somatic maintenance (and thus longevity and future reproduction) and the resources available for current reproduction. Evidence shows that the evolved capacity of somatic cells to carry out effective maintenance and repairs (e.g., DNA

\footnotetext{
${ }^{8}$ The color change that peppered moths underwent during the 19th century is a classic example of evolution in nature [See Kettlewell 1973]. Before the Industrial Revolution light-colored English peppered moths blended with the lichen-covered bark of trees. By the end of the 19th century a black variant of the moth, first recorded in 1848, became far more prevalent than the lighter varieties in areas in which industrial carbon removed the lichen and changed the background color. Hence, a significant evolutionary change occurred within a time period that correspond to only hundreds of generations. Moreover, evidence from Daphne Major in the Galapagos suggests that significant evolutionary changes in the distribution of traits among Darwin's Finches occurred within few generations due to a major drought [Grant and Grant 1989]. Other evidence, including the dramatic changes in the color patterns of guppies within 15 generations due to changes in the population of predators, are surveyed by Endler [1986].

${ }^{9}$ See Livingston [1958], Weisenfeld [1967] and Durham [1982].

${ }^{10}$ See Stearns (1992).
} 
repairs, accurate gene regulation, tumor suppression, and antioxidants), governs the time taken for damage to accumulate thereby regulating longevity. ${ }^{11}$ Experiments and observation in nonhuman species indicate that this trade-off exists. ${ }^{12}$ Moreover, using a historical data set from the British aristocracy, Westendorp and Kirkwood (1998) argue that human life histories involve a trade-off between longevity and reproduction.

The theory focuses on the evolutionary process with respect to the trade-off between parental somatic investment in each offspring and the number of offspring that can be supported. ${ }^{13}$ Resources that are channeled towards higher somatic investment in each offspring generate higher life expectancy, but limit the number of offspring that can be raised. "Increased bearing is bound to be paid for by less efficient caring" [Dawkins 1989, p. 116]. Thus, there is an evolutionary trade-off, regarding reproduction success, between the life expectancy of each offspring and the number of offspring that can be supported. ${ }^{14}$ Similar insights would be obtained if one would have alternatively focused on the evolutionary process with respect to the trade-off between the resources allocated to current parental own somatic investments (and thus life expectancy and future reproduction success) and the resources invested in current parental reproduction.

The probability that an individual would survive to a reproduction age, is affected positively by the genetically pre-determined somatic investment, and negatively by the extrinsic

\footnotetext{
${ }^{11}$ Evidence at the molecular and cellular levels suggest that longevity is correlated with effort devoted to repair and cellular maintenance. A positive correlation is found among captive mammals between longevity and DNA repair capacity, genomic integrity, and mitochodrial ROS production. Furthermore, cell resistance to external stress is larger among long-lived species. Moreover, it should be noted that long-run adaptations that reduce extrinsic mortality (e.g., larger brains) are generally linked to increased longevity. [Kirkwood (1998)]. These long-run adaptations, however, are not the focus of the current study.

${ }^{12}$ See the survey of this evidence by Williams and Day (2003).

${ }^{13} \mathrm{As}$ is well established in the evolutionary biology literature since the seminal work of Lack [1954], the allocation of resources between offspring 'caring' and 'bearing' is subjected to evolutionary changes. Lack (1954) suggests that clutch sizes (e.g., number of eggs per nest), among owls and other predatory vole-eating birds, for instance, are positively related to food abundance. He argues that the clutch size is selected such that under any feeding conditions fertility rates ensure the maximal reproductive success. Furthermore, Cody [1966] documents the existence of significant differences between clutch sizes of the same bird species on islands and nearby mainland localities of the same latitude. In temperate regions where food is more abundant in the mainland than on islands, the average clutch size is smaller on the islands. For instance, Cyanoramphus novaezelandeae, the average mainland clutch is 6.5 whereas the average in the island is 4 .

${ }^{14}$ Consistent with the existence of this trade-off, recent molecular and behavioral genetic research across historical and modern data from the United States and Europe suggests that fertility behavior has a significant hereditary component [Rodgers et al. 2001a]. For instance, as established recently by Kohler et al. [1999] and Rodgers et al. [2001b] based on the comparison of fertility rates among identical and fraternal twins born in Denmark during the periods 1870-1910 and 1953-1964, slightly more than one-quarter of the variance in completed fertility is attributable to genetic influence. These findings are consistent with those of Rodgers and Doughty [2000] based on kinship data from the United States.
} 
mortality risk that is associated with socio-environmental characteristics, such as population density. Variations in somatic investment may manifest themselves in genetically pre-determined variations in the length of childhood and therefore in the amount of parental resources that are devoted to each offspring.

The rise in mortality risk triggers a process of natural selection that alters the distribution of types within the population. Nature selects the life-history profile and thereby life expectancy that maximizes reproduction success in any given environment, and the distribution of these hereditary life-history traits evolves over time due to changes in the environment. As long as the adverse effect of population density on the survival probability is lower for individuals who are genetically pre-disposed for higher somatic investment, the evolutionary optimal level of somatic investment is an increasing function of the extrinsic mortality risk. Thus, the evolutionary process within the human population may lead to a reduction in mortality rates and an increase in life expectancy, despite the increase in extrinsic mortality risk.

The theory proposes that individuals who are characterized by low somatic investment and thus low life expectancy have an evolutionary advantage in an environment that is characterized by low population density, whereas those characterized by high somatic investment and thus high life expectancy have an evolutionary advantage in an environment that is characterized by a high population density. Hence, as population density increased in the process of development, increasing the extrinsic mortality risk, the evolutionary advantage shifted from individuals with low somatic investment and thus low life expectancy to those with high somatic investment and high life expectancy. Furthermore, the increase in population density and its interaction with the forces of natural selection induce a non-monotonic time path of life expectancy. As population density increased and the extrinsic mortality risk raised, life expectancy declined as long as the distribution of types in the population has not evolved considerably. Ultimately, however, individuals with higher life expectancy dominate the population and life expectancy raised. Moreover, the biological upper bound of longevity increased, generating the biological infrastructure for the recent prolongation of life expectancy that was brought about by the decline in the extrinsic mortality risk due to improvements in medical technology. 


\section{Related Literature}

Evolutionary biologists suggest two complementary theories for the evolution of senesces (i.e., persistent decline in the somatic function of an organism with age) and thus of life expectancy based on the premise that selection weakens with age. ${ }^{15}$ The mutation accumulation theory of aging [Medawar, 1946] suggests that late-acting deleterious mutations have a smaller negative effect on the survival of the genes and aging therefore is an inevitable outcome of the declining force of natural selection in older age. The antagonistic pleiotropy theory [Williams, 1957] suggests that late-activating deleterious genes may be favored by natural selection and may be actively accumulated in population if they have a beneficial reproductive effects in early stages of life. In particular, the disposable soma theory [Kirkwood and Holliday, 1979] examines the optimal allocation of metabolic resources between reproduction and maintenance.

The proposed theory advances the disposable soma theory, exploring the implications of the process of economic development on the evolution of the distribution of life-history profiles (i.e., the life cycle of somatic investment and maintenance) within the human species. The proposed theory demonstrates that if the effect of a rise in the extrinsic mortality risk on the survival probability can be mitigated by an increase in somatic investment, then it would necessarily generate an increase in the (evolutionary optimal) level of somatic investment and may thereby prolong longevity. Most of the literature in evolutionary biology focused on the effect of a rise in the extrinsic mortality rate that cannot be mitigated by an increase somatic investment, arguing therefore that in this type of environment an increase in the extrinsic mortality rate would generate a decline in somatic investment and thereby a decline in life expectancy. Recently, however, in light of a wide range of compelling evidence, it has been recognized that the adverse effect of a rise in extrinsic mortality risk can be counteracted by an increase in somatic investment [Williams and Day (2003)].

The implications of the interaction between the process of economic development and human evolution have been explored in recent years. ${ }^{16}$ Galor and Moav (2002) suggest that during the epoch of Malthusian stagnation traits of higher valuation for offspring quality generated an

\footnotetext{
${ }^{15}$ An earlier theory that is widely considered among biologists as inconsistent with the evidence is the theory of programmed death (Weismann, 1882). It suggests that aging is beneficial and even necessary at the species level in order to free resources for the younger generation.

${ }^{16}$ The evolution of a wide range of attributes such as time preference, risk aversion, and altruism, in a given economic environment, has been extensively explored in the economic literature, as surveyed by Bowles (1998) and Robson (2001).
} 
evolutionary advantage and their representation in the population gradually increased. This selection process and its effect on investment in human capital stimulated technological progress and ultimately triggered a reinforcing interaction between investment in human capital and technological progress that brought about the demographic transition and the state of sustained economic growth. ${ }^{17}$ Ofek (2001) and Saint Paul (2003) examine the effect of the emergence of markets on the evolution of heterogeneity in the human population. Clark and Hamilton (2003) analyze the relationship between the evolution of time preference and the process of development, Lagerlof (2004) examines the evolution of human body size in the process of development, and Borghans, Borghans and ter-Weel (2004) analyze the effect of human cooperation on the evolution of Major Histocompatibility Complex (MHC). ${ }^{18}$

Abstracting from the process of economic development, Robson and Kaplan (2003) examine the evolutionary optimal human brain size and life expectancy in the context of hunter-gatherer societies that were prevalent during the two million years that preceded the Agricultural Revolution. They argue that a decrease in the extrinsic mortality risk that was faced by the human population led to an increase in somatic investment leading to larger brain size and higher life expectancy. In contrast to the basic premise of Robson and Kaplan (2003) that the extrinsic mortality risk decreased in the course of human existence, evidence about the rise of population density and the lack of significant improvements in technology prior to the Mesolithic period, suggests in fact that extrinsic mortality risk increased in this era. For instance, the transition from the Paleolithic period to the Mesolithic hunter-gatherer economies corresponded to the disappearance of large game animals and the consequent adoption of broad spectrum foraging patterns aimed at a wider array of small animals, seeds, and aquatic foods resulting in a decline in nutrition and thus human health [Cohen (1989), and Acsa'di and Nemeskeri (1970, p. 169)]. Our theory, in contrast, argues that an increase in the extrinsic mortality risk leads in fact to higher somatic investment, that mitigates the negative effect of the external environment, leading eventually to a higher life expectancy. The theory thereby is consistent with the observed

\footnotetext{
${ }^{17}$ The theory is applicable for either social or genetic intergenerational transmission of traits. A cultural transmission is likely to be more rapid and may govern some of the observed differences in fertility rates across regions. The interaction between cultural and genetic evolution is explored by Boyd and Richardson (1985) and Cavalli-Sforza and Feldman (1981), and a cultural transmission of preferences is examined by Bisin and Verdier (2000).

${ }^{18}$ The Darwinian methodology has been employed in the study of human behavior within the sociobiology literature (e.g., Wilson [1975]) and in a sequence of studies about the evolution of preferences surveyed by Bowles [1998] and Robson [2001], within the economics literature. The focus of these models is fundamentally different. They are primarily designed to explain the determination of preference (e.g., Becker [1976], and Hansson and Stuart [1990]).
} 
increased in life expectancy since the origin of the human species, although, unlike Robosn and Kaplan (2002) it is based on the premise that the extrinsic mortality risk increase over this period. Moreover, the theory offers an explanation for the observed non-monotonic evolution of life expectancy in the context of the Agricultural Revolution as well as in the urbanization process, despite an apparent increase in the extrinsic mortality risk during these periods of increased population density.

Finally, in contrast to our evolutionary approach to the understanding of the non-monotonic time-path of life expectancy in the last 10,000 year, existing economic theories have focused on the contribution of the advancement of health infrastructure, medical technology and education to the rise in life expectancy in recent centuries, as documented by Fogel (1994) and Mokyr (1998). Various theories examined formally mechanisms that capture the interaction between human capital formation, the decline in mortality rate, and the rise in life expectancy, in the process of development. Erlich and Lui (1991), Galor and Weil (1999), Kalemli-Ozcan, Ryder and Weil (2000), Boucekkine, de la Croix and Licandro (2003), Cervellati and Sunde (2003), Lagerlof (2003), Hazan and Zoabi (2004), Soares (2003), Weisdorf (2004), and Iyigun (2005) focus on the plausible role of the reinforcing interaction between life expectancy and human capital formation in the transition from stagnation to growth.

\section{The Basic Structure of the Model}

Consider an overlapping generations economy in which economic activity is extended over infinite discrete time. The economy consists of a variety of individuals that are distinguished genetically by the resources that they allocate to somatic investment, repair and maintenance, and thereby by their life expectancy. Resources that are channeled towards higher somatic investment of each offspring generate higher life expectancy, but limit the number of offspring that can be raised. Thus, there is an evolutionary trade-off, regarding reproduction success, between the life expectancy of each offspring and the number of offspring that can be supported.

The economy is characterized by a Malthusian environment in which the effect of technological progress on the growth of income per capita is constrained by the increase in the size of the population, whereas population size is constrained by the availability of resources as well as by the technological level.

The increase in the size of the population that is facilitated by technological progress 
generates two adverse effect on future population growth. It reduces future income per capita and thus lowers fertility (the "preventative check") and it increases population density, raising mortality rates (the "positive check"). However, this rise in mortality risk triggers a process of natural selection that alters the distribution of types within the population. Nature selects the life-history profile (i.e., the life cycle of somatic investment) and thereby life expectancy that maximizes reproduction success, in any given environment and the distribution of these hereditary life-history traits evolves over time due to changes in the environment that are induced by increases in population density. Thus, the evolutionary process within the human population may lead to a reduction in mortality rates and an increase in life expectancy, despite the increase in extrinsic mortality risk that is associated with the rise in population density.

\subsection{Individuals}

In each period a new generation of individuals is born. Reproduction is a-sexual and each individual is therefore born to a single parent. ${ }^{19}$ Individuals are ex-ante identical in all respects except for the genetic variation in somatic investment and the associated life expectancy. Individuals may live for either one period (childhood) or two periods (childhood and adulthood), i.e., children are subjected to a mortality risk that may prevent them from reaching adulthood. In their childhood, individuals consume part of their parental income. Those who survive and reach adulthood, work and allocate their income to consumption and child rearing.

\subsubsection{Somatic Investment, Extrinsic Mortality, and Life Expectancy}

The survival probability of individuals depends upon their somatic investment and the extrinsic mortality risk that characterizes the environment in which they live. Individuals are distinguished by the resources that they allocate to somatic investment, repair, and maintenance, and thereby by their life expectancy. Individuals that are characterized by a higher, genetically predetermined, somatic investment generate higher life expectancy. Variations in somatic investment may manifest themselves in genetically pre-determined variations in the length of childhood and therefore in the amount of parental resources that are devoted to each offspring. For simplicity, it is assumed that the somatic investment of individual of type $i$ during childhood is $\mu^{i}{ }^{20}$ This

\footnotetext{
${ }^{19}$ The modeling of sexual reproduction would cluter the analysis, but would not alter the basic hypothesis.

${ }^{20}$ Clearly, the level of somatic investment of a given type may reflect a rigid component that is unaffected by the environment, as well as a flexible one that may react to the existing environment and individual choice. Although the model abstracts from the existence of flexible components, as would become apparent the qualitative analysis
} 
genetic trait is transmitted from parent to offspring of type $i$ with probability $\rho \rightarrow 1$.

The survival probability of each type of individual depends upon the extrinsic mortality risk that is associated with the environment and the individual's genetically pre-determined somatic investment. The extrinsic mortality risk, $x_{t}$, is positively affected by population density, as reflected by the population size, $L_{t}$, and negatively by a variable, $S$, that capture the level of health infrastructure, as well as environmental, social, and technological attributes, ${ }^{21}$

$$
x_{t}=x\left(L_{t} ; S\right)
$$

Population density has an adverse effect on the survival probability only beyond a critical level $\bar{L}(S)$, i.e.,

$$
d x_{t} / d L_{t}\left\{\begin{array}{lll}
=0 & \text { if } & L_{t} \leq \bar{L}(S) \\
>0 & \text { if } & L_{t}>\bar{L}(S)
\end{array}\right.
$$

and $\lim _{L_{t} \rightarrow \infty} x\left(L_{t} ; S\right)=1$.

The probability that individual of type $i$ of generation $t$ would survive to adulthood, $P_{t}^{i}$, is affected positively by the genetically pre-determined somatic investment in childhood, $\mu^{i}$, and negatively by an index, $x_{t} \in[0,1]$, that captures the extrinsic mortality risk;

$$
P_{t}^{i}=P\left(\mu^{i}, x_{t}\right)
$$

Thus, the life expectancy of individual of type $i$ of generation $t, E_{t}^{i}=1+P_{t}^{i}$, is affected positively by the genetically pre-determined somatic investment in childhood, $\mu^{i}$, and negatively by the extrinsic mortality risk, $x_{t}$;

$$
E_{t}^{i}=E\left(P\left(\mu^{i}, x_{t}\right)\right)
$$

The biological upper bound on life expectancy for individual of type $i, E_{\max }^{i}$, is reached when the extrinsic mortality risk is equal to zero, i.e.,

$$
E_{\max }^{i}=E\left(P\left(\mu^{i}, 0\right)\right) .
$$

would not be affected if a flexible component would be integrated into the analysis.

${ }^{21}$ Variations in socioeconomic organizations (e.g., hunter-gatherers, agricultural society, urban society) may alter the relationship between population size and "effective" population density. In particular, the transitions from a hunter gatherer society to an agricultural one and from a rural society to an urban one increase the effective population density (for a given population size) and thus the extrinsic mortality risk 
Individuals whose genetically determined somatic investment is below a threshold $\bar{\mu}\left(x_{t}\right)$ would not survive and their type would become extinct. That is,

$$
P_{t}^{i}=P\left(\mu^{i}, x_{t}\right)\left\{\begin{array}{lll}
>0 & \text { if } & \mu^{i}>\bar{\mu}\left(x_{t}\right) \\
=0 & \text { if } & \mu^{i} \leq \bar{\mu}\left(x_{t}\right),
\end{array}\right.
$$

where for all $x_{t} \in[0,1], \bar{\mu}\left(x_{t}\right)>0$. Moreover, for $\mu^{i}>\bar{\mu}\left(x_{t}\right), P_{\mu}\left(\mu^{i}, x_{t}\right)>0, P_{\mu \mu}\left(\mu^{i}, x_{t}\right)<0$, $P_{x}\left(\mu^{i}, x_{t}\right) \leq 0$ and

(a) the threshold level of somatic investment below which individuals do not survive, $\bar{\mu}\left(x_{t}\right)$, increases with the harshness of the environment, i.e.,

$$
\bar{\mu}^{\prime}\left(x_{t}\right)>0
$$

(b) the adverse effect of population density on the survival probability is (weakly) lower for individuals who are genetically pre-disposed for higher somatic investment and somatic investment increases the probability of survival in decreasing rates, i.e.,

$$
P_{x \mu}\left(\mu^{i}, x_{t}\right) \geq 0 \quad \text { for } \mu^{i}>\bar{\mu}\left(x_{t}\right)
$$

(c) the elasticity, $\eta_{P_{\mu}, \mu^{i}}$, of the effect of somatic investment on the survival probability, $P_{\mu}\left(\mu^{i}, x_{t}\right)$, with respect to somatic investment, $\mu^{i}$, is smaller than one in absolute value (i.e. an increase in somatic investment, $\mu^{i}$ generates less than a proportional decrease in the effect of somatic investment on the survival probability, $\left.P_{\mu}\left(\mu^{i}, x_{t}\right)\right) .{ }^{22}$

$$
\eta_{P_{\mu}, \mu^{i}} \equiv\left|\frac{P_{\mu \mu}\left(\mu^{i}, x_{t}\right) \mu^{i}}{P_{\mu}\left(\mu^{i}, x_{t}\right)}\right|<1 \quad \text { for } \mu^{i}>\bar{\mu}\left(x_{t}\right) .
$$

\subsubsection{Fertility Across Types}

Consistent with the Darwinian theory, preferences (of each adult individual) are defined over their own consumption and the expected number of their offspring who would reach the reproduction age. ${ }^{23}$ Preferences are identical across types and generations. The preferences of each individual of type $i$ of the adult generation in period $t$ are represented by the utility function

$$
u_{t}^{i}=(1-\beta) \ln c_{t}^{i}+\beta \ln P_{t}^{i} n_{t}^{i} ; \quad \beta \in(0,1),
$$

\footnotetext{
${ }^{22}$ That is, for $\mu^{i}>\bar{\mu}\left(L_{t}\right)$, the survival probability $P\left(\mu^{i}, L_{t}\right)$ is only "moderately" strictly concave function of $\mu^{i}$.

${ }^{23}$ Consistent with the Darwinian theory, therefore, individuals are implicitly assumed to be risk neutral with respect to the number of offspring (See Robson (2002)).
} 
where $c_{t}^{i}$ is the consumption of individual of type $i$ of the adult generation $t$ and $P^{i} n_{t}^{i}$ is the expected number of the individual's surviving offspring. ${ }^{24}$

These preferences capture the most fundamental trade-offs that exist in nature. Namely, the trade-off between resources allocated to the parent and to the offspring, ${ }^{25}$ and the trade-off between the number of offspring and resources allocated to assure the survival of each offspring.

Individuals of all types who are born in period $t-1$ and survive to the second period of life, generate an income of $y_{t}$. Consistent with the determinants of income in a Malthusian environment (Malthus (1798)) that is characterized by scarcity of land, individuals' income, $y_{t}$, is affected positively by the technological level, $A_{t}$, and negatively by the size of the working age population, $L_{t}$. In particular, income per worker is ${ }^{26}$

$$
y_{t}=\left(A_{t} / L_{t}\right)^{\alpha} \equiv y\left(A_{t}, L_{t}\right)
$$

Given their preference, individuals' income, $y_{t}$, is allocated between consumption and child rearing. In particular, members of type $i$ of the adult generation $t$ divide their income, $y_{t}$, between consumption, $c_{t}^{i}$, and the cost associated with raising $n_{t}^{i}$ children of type $i, \mu^{i} n_{t}^{i}$, where $\mu^{i}$ is the somatic investment of an individual of type $i$ during childhood. The budget constraint of individuals of type $i$ in the second period of life is therefore ${ }^{27}$

$$
\mu^{i} n_{t}^{i}+c_{t}^{i} \leq y_{t}
$$

Members of type $i$ of the adult generation $t$ choose the number of their children and their own consumption, so as to maximize their utility function subject to the budget constraint.

\footnotetext{
${ }^{24}$ Although parental preferences are defined over the number of surviving offspring they cannot affect the survival probability of each offspring (i.e., the level of somatic investment in each offspring reflects fundamental biological needs that cannot be altered by parental choice.) The introduction of an additional component of somatic investment that reflects parental choice would not alter the qualitative analysis, as long as the offspring genetic make-up plays a significant role in the determination of the survival probability.

${ }^{25}$ Resources allocated to parental consumption may be viewed as a force that raises parental productivity and resistance to adverse shocks (e.g., famine and disease), generating a positive effect on the fitness of the parent and the survival of the lineage. This positive effect, however, is counterbalanced by the implied reduction in resources allocated to the offspring, generating a negative effect on the survival of the lineage. For simplicity, the parent is not subjected to a subsistence consumption constraint.

${ }^{26}$ This formulation of income per capita is consistent with an aggregate production function of the form $Y_{t}=L_{t}^{1-\alpha}$ $\left(A_{t} T\right)^{\alpha}$, where $T$ is a stock of (free) land that is normalized to 1 .

${ }^{27}$ If some non-surviving children will parish in the beginning of the childhood period, rather than in the end, as it is currently assumed, no qualitative change will occur. The cost of those non-surviving children will be zero, and therefore, $n_{t}^{i}$ will stand for the number of surviving children that completed their childhood period. Furthermore, the incorporation of time as well as real resources as inputs in the production of offspring would not affect the analysis qualitatively, as shown in the next footnote.
} 
Hence, the number of children of individual of type $i$ in period $t$ is

$$
n_{t}^{i}=\beta y_{t} / \mu^{i}
$$

Thus, consistent with the fundamental feature of the Malthusian environment - the environment that is at the center of the theory - the number of children is an increasing function of parental income. ${ }^{28}$ In addition, the number of children is lower among types that require a larger somatic investment.

\subsection{Evolutionary Optimal Life Expectancy in a Stationary Environment}

This section examines the individual type that has an evolutionary advantage (i.e., the largest number of surviving offspring) in a given environment, $x_{t}$. This type will dominate the population in the long run, provided that the environment will remain stationary.

Let, $\mu_{t}^{*}$, be the genetically determined level of somatic investment that, given the individual resource constraint (10), will generate the largest number of surviving offspring, $P\left(\mu^{i}, x_{t}\right) n_{t}^{i}$, and let $P_{t}^{*}=P\left(\mu_{t}^{*}, x_{t}\right)$ be the evolutionary optimal level of life expectancy. It follows that

$$
\begin{array}{rrl}
\mu_{t}^{*}= & \arg \max P\left(\mu^{i}, x_{t}\right) n_{t}^{i} \\
& \text { s.t. } & n_{t}^{i}=\beta y_{t} / \mu^{i}
\end{array}
$$

Lemma 1 The genetically determined level of somatic investment, $\mu_{t}^{*}$, that generates the largest number of surviving offspring, is a unique single-valued function of the environment, $x_{t}$ :

$$
\mu_{t}^{*}=\mu^{*}\left(x_{t}\right)>\bar{\mu}\left(x_{t}\right)
$$

and the evolutionary optimal level of life expectancy, $E_{t}^{*}$, is therefore

$$
E_{t}^{*}=E\left(P\left(\mu^{*}\left(x_{t}\right), x_{t}\right)\right)
$$

Proof. Since $P_{t}^{i}=P\left(\mu^{i}, x_{t}\right)=0$ for $\mu^{i} \leq \bar{\mu}\left(x_{t}\right)$, it follows that $\mu^{*}\left(x_{t}\right)>\bar{\mu}\left(x_{t}\right)$. Further, as follows from the first order conditions for the maximization problem (11), for $\mu^{*}\left(x_{t}\right)>\bar{\mu}\left(x_{t}\right)$,

$$
F\left(\mu_{t}^{*}, x_{t}\right) \equiv P_{\mu}\left(\mu_{t}^{*}, x_{t}\right) \mu_{t}^{*}-P\left(\mu_{t}^{*}, x_{t}\right)=0 .
$$

\footnotetext{
${ }^{28}$ See for instance, Boyer (1989) and Clark and Hamilton (2003). The positive effect of the parental income on the number of children, regardless of the level of income, reflects the assumption that child rearing is associated with a real cost, without any time cost. If a time cost would be added, it would generate the Malthusian structure in low levels of income but fertility rates will be bounded in a higher level of income. In particular, let $\tau^{i}$ be the time cost associated with an offspring of parent of type $i$. Individual $i^{\prime} s$ budget constraint would become $n_{t}^{i}\left(y_{t} \tau^{i}+\mu^{i}\right)+c_{t}^{i} \leq y_{t}$ and the optimization would imply that $n_{t}^{i}=\beta y_{t} /\left(\tau^{i} y_{t}+\mu^{i}\right)$. Hence, as in the formulation without a time cost, the number of children is an increasing function of income and a decreasing function of somatic investment. However, under this specification, the number of children is a strictly concave function of income, bounded from above by $\beta / \tau^{i}$.
} 
Hence, since $F_{\mu}\left(\mu_{t}^{*}, x_{t}\right)=P_{\mu \mu}\left(\mu_{t}^{*}, x_{t}\right) \mu_{t}^{*} \neq 0$, the lemma follows from the Implicit Function Theorem and the definition of life expectancy.

As follows from (12), the evolutionary optimal level of somatic investment, $\mu^{*}\left(x_{t}\right)$, depicted in Figure 3, is given by the unique tangency point between the function $P\left(\mu^{i}, x_{t}\right)$ and a ray from the origin.

Proposition 1 As depicted in Figure 3,

- Under A1 and A2, the evolutionary optimal level of somatic investment is an increasing function of the extrinsic mortality risk, i.e.,

$$
\mu^{* \prime}\left(x_{t}\right)>0
$$

- Under A1-A3, the evolutionary optimal level of life expectancy is an increasing function of the extrinsic mortality risk, i.e.,

$$
\frac{d E\left(P\left(\mu^{*}\left(x_{t}\right), x_{t}\right)\right)}{d x_{t}}>0
$$

- Under A1-A2, the evolutionary optimal biological upper bound of life expectancy is an increasing function of the extrinsic mortality risk, i.e.,

$$
\frac{d E\left(P\left(\mu^{*}\left(x_{t}\right), 0\right)\right)}{d x_{t}}>0
$$

Proof. See Appendix. ${ }^{29}$

The evolutionary optimal level of somatic investment is an increasing function of the extrinsic mortality risk since the threshold level of somatic investment that permits survival is an increasing function of the extrinsic mortality risk (Figure 3). As long as the adverse effect of population density on the survival probability is (weakly) lower for individuals who are genetically pre-disposed for higher somatic investment (i.e., as long as (A2) is satisfied), the increase in the

\footnotetext{
${ }^{29}$ For instance, if

$$
P\left(\mu^{i}, x_{t}\right) \begin{cases}0 & \text { for } \quad \mu^{i} \leq x_{t} \\ \left(\mu^{i}-x_{t}\right)^{1 / 2} & \text { for } \quad \mu^{i} \in\left(x_{t}, x_{t}+1\right) \\ 1 & \text { for } \quad \mu^{i}>x_{t}+1\end{cases}
$$

for $x \in(0,1)$, then

$$
\mu^{*}\left(x_{t}\right)=2 x_{t}
$$$$
P_{t}^{*}=x_{t}^{1 / 2}
$$

and $\mu^{* \prime}\left(x_{t}\right)>0$ and $d P\left(\mu^{*}\left(x_{t}\right), x_{t}\right) / d x_{t}>0$.
} 
minimal somatic investment, $\bar{\mu}\left(x_{t}\right)$, that is associated with a transition to a harsher environment, implies that the evolutionary optimal investment in each offspring is larger (i.e., the tangency between the function $P\left(\mu^{i}, x_{t}\right)$ and a ray from the origin in Figure 3, would necessarily occur at a higher level of $\mu) .{ }^{30}$

The evolutionary optimal level of life expectancy is an increasing function of the extrinsic mortality risk if an increase in somatic investment, $\mu^{i}$ generates less than a proportional decrease in the effect of somatic investment on the survival probability, $P_{\mu}\left(\mu^{i}, x_{t}\right)$ (i.e., if (A3) is satisfied). ${ }^{31}$

The evolutionary optimal biological upper bound of life expectancy is an increasing function of the extrinsic mortality risk since the evolutionary optimal level of level of somatic investment is an increasing function of the extrinsic mortality risk and higher somatic investment has a positive effect on the survival probability.

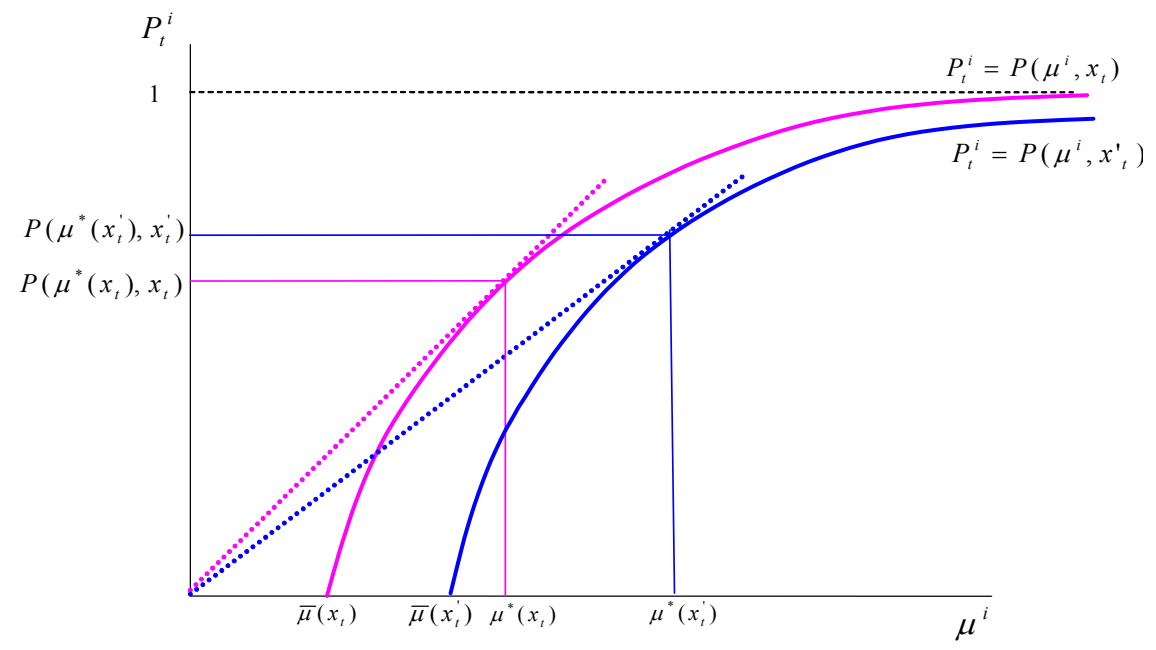

Figure 3: Evolutionary optimal levels of somatic investment and survival probability for different levels of extrinsic mortality risk, where $x_{t}^{\prime}>x_{t}$

It follows from Lemma 1 and Proposition 1 that an increase in the extrinsic mortality risk will induce a process of natural selection that will gradually increase somatic investment, life expectancy and the biological upper bound of life expectancy. Once this evolutionary process will complete its course, a rapid improvement in the health infrastructure that would decrease

\footnotetext{
${ }^{30}$ For instance, if in contrast to (A2), the extrinsic component of the survival rate is independent of somatic investment, i.e., the survival probability to adulthood $P(\mu, x)=p(\mu)(1-x)$, then $P_{\mu x}=-p_{\mu}<0$ and the optimal somatic investment is negatively affected by the extrinsic mortality risk.

${ }^{31}$ It should be noted that (A3) is a sufficient but not a necessary condition, as is apparent from the example in footnote 29 .
} 
the extrinsic mortality risk will generate an additional significant improvement in life expectancy (prior to the reversal in the evolutionary process).

Thus, the gradual rise in population density in the process of development since the agricultural revolution, increased the extrinsic mortality risk that was faced by the human population and therefore triggered a gradual increase in life expectancy. Moreover, the biological upper bound of longevity increased, generating the biological infrastructure for the recent prolongation of life expectancy that was brought about by the decline in the extrinsic mortality risk due to improvements in medical technology.

\section{The Dynamics of Population, Technology and Life Expectancy}

This section examines the interaction between population growth, technological change and the evolution of life expectancy in a Malthusian economy. It analyzes the effect of the Malthusian feedback between technological progress and population growth, and the associated increase in population density and extrinsic mortality, on somatic investment, life expectancy, until the recent improvements in medical technology that were associate with the escape from the Malthusian epoch.

\subsection{The Evolution in the Distribution of Types}

Consider an economy in period 0 . Consistent with the observation that population density prior to the Agricultural Revolution is rather low and has a negligible effect on the spread of infectious diseases, it is assumed that population density prior to the Agricultural Revolution was below the threshold $\bar{L}=\bar{L}(S)$, above which an increase in population increases the extrinsic mortality risk, and the index of environmental effect on the survival probability is constant at a level $x=0 .{ }^{32}$ Hence, as follows from Lemma 1, the economy in period 0 is dominated by an individual whose somatic investment is $\mu^{*}(0)$.

\subsubsection{Somatic Investment and Survival Probability Across Types}

Suppose that $\mu^{*}(0)$ is the somatic investment of individual of type $b$, i..e., $\mu^{b}=\mu^{*}(0)$. Individuals of type $b$, therefore, have the largest number of surviving offspring in every time period (at least) prior to period 0 , and they therefore dominate the population in period 0 .

\footnotetext{
${ }^{32}$ Since the theory focuses at the effect of population density on the survival probability and thus on the evolutionary process, the vector $S$ is assumed to remain stationary from period 0 .
} 
As follows from the properties of (3), the probability that an individual of type $b$ of generation $t$ will survive to adulthood, $P_{t}^{b}$, is a decreasing function of the population size, $L_{t}$, beyond a threshold $\bar{L}$, i.e.,

$$
P_{t}^{b}=P\left(\mu^{b}, x\left(L_{t} ; S\right)\right) \equiv P^{b}\left(L_{t}\right)
$$

where, as follows from the properties of (3) and (1),

$$
P^{b}\left(L_{t}\right) \begin{cases}=0 & \text { for } \quad L<\bar{L} \\ <0 & \text { for } L>\bar{L}\end{cases}
$$

and it is further assumed that for $\theta \in(0,1)$

$$
P\left(\mu^{b}, 1\right)<\theta \text { and } P\left(\mu^{b}, 0\right) \in(\theta, 1)
$$

Hence, since $\lim _{L_{t} \rightarrow \infty} x\left(L_{t} ; S\right)=1$, it follows that

$$
\lim _{L \rightarrow \infty} P^{b}(L)<\theta \text { and }, P^{b}(L) \in(\theta, 1) \quad \forall L \leq \bar{L} .
$$

Individuals of type $b$ give birth to children of type $b$ with a probability $\rho \rightarrow 1$. However, with an infinitesimal probability $(1-\rho)$ they give birth to children of a different type - type $a$. The population, therefore, remains heterogeneous in any time period and its distribution is affected by evolutionary pressure. ${ }^{33}$ Type $a$ is characterized by a higher level of somatic investment, $\mu^{a}>\mu^{b}$, that is optimal in some level of a harsher environment $x^{\prime} \in(0,1] .{ }^{34}$ Hence, as follows from Proposition 1, the life expectancy of individual of type $a$ in the environment, $x^{\prime}$ is higher than the life expectancy of individuals of type $b$ in the environment $x=0$. In particular, to simplify the exposition, the level of somatic investment of individuals of type $a$ is assumed to be optimal in the harshest environment, $x=1$, and the probability that an individual of type $a$ of generation $t$ will survive to adulthood in this environment, $P\left(\mu^{*}(1), 1\right)$, is normalized to $1 .^{35}$ Hence,

\footnotetext{
${ }^{33}$ The existence of a large number of types would not affect the qualitative

analysis about the evolution of life expectancy in the process of development. The presence of two types of individuals simplifies the exposition considerably and permits the analysis of the effect of a single distributionparameter on the evolution of this dynamical system. The generalization for continuum of types is feasible since as established in Proposition 1, the evolutionary optimal level of life expectancy increases monotonically with the harshness of the environment, $x_{t}$.

${ }^{34}$ As will become apparent, population density would increase in a Malthusian environment, and as established in Proposition 1, an individual type with higher somatic investment would gain an evolutionary advantage. Thus, without loss of generality it is assumed that offspring's deviations from parental type $b$ are only towards higher somatic investment.

${ }^{35}$ The normalization of survival probability of individual of type $a$ to 1, prevents an explicit analysis of the effects of a change in extrinsic mortality risk on the biological upper bound of longevity of type $a$. However, Since the focus of this section is on the evolution of life expectancy within the Malthusian epoch, abstracting from the effect of recent improvement in medical technology on life expectancy this assumption is not an obstacle. The previous section discusses the forces that contributed to the rise in life expectancy in the last 150 years.
} 


$$
\begin{gathered}
\mu^{a}=\mu^{*}(1) ; \\
P_{t}^{a}=1 \quad \forall t .
\end{gathered}
$$

\subsubsection{Fertility and Evolutionary Advantage Across types}

The ratio between the number of offspring of the two types of individuals, as follows from (10), is

$$
\frac{n_{t}^{a}}{n_{t}^{b}}=\frac{\mu^{b}}{\mu^{a}} \equiv \theta \in(0,1)
$$

Since the number of individuals of type $i$ grows at a gross rate of $P_{t}^{i} n_{t}^{i}$, the gross growth in the number of individuals of type $b$ relative to the number of individuals of type $a, \gamma_{t}$, is

$$
\gamma_{t} \equiv \frac{P_{t}^{b} n_{t}^{b}}{P_{t}^{a} n_{t}^{a}}
$$

Lemma 2 Under A4, there exists a unique population size, $\hat{L}>\bar{L}$, such that the fraction of individuals of each type remains stationary, i.e.,

$$
\gamma_{t}=1 \quad \text { if and only if } L_{t}=\hat{L}
$$

where $P^{b}(\hat{L})=\theta$.

Proof. Follows directly from (13),(??),(17), and (18), noting, A4.

Proposition 2 Under A4,

- Individuals of type b, that are characterized by low somatic investment and thus low life expectancy, have an evolutionary advantage in an environment that is characterized by low population density, i.e.,

$$
\gamma_{t}>1 \quad \text { if and only if } L_{t}<\hat{L}
$$

- Individuals of type a, that are characterized by high somatic investment and thus high life expectancy, have an evolutionary advantage in an environment that is characterized by a high population density, i.e.,

$$
\gamma_{t}<1 \quad \text { if and only if } L_{t}>\hat{L}
$$

Proof. The proposition is a corollary of Lemma 2, noting A4. 
Proposition 3 If population density increases in the process of development, increasing the extrinsic mortality risk, then, provided that $L_{0}<\bar{L}$ and ultimately $L_{t}>\hat{L}$, under $A 4$,

- The evolutionary advantage shifts from individuals of type b, with low somatic investment and thus low life expectancy, to individuals of type a, with high somatic investment and high life expectancy.

- Life expectancy evolves non-monotonically as population density increases:

i. It is constant as long as population density is below the threshold $\bar{L}$ (i.e., life expectancy of the dominating type in the population, type $b$, is unaffected by the increase in population since population density is insignificant)

ii. It declines once population density is above the threshold $\bar{L}$ (i.e., life expectancy of the dominating type in the population, type $b$, declines due to the increase in extrinsic mortality risk)

iii. It increases once population density is sufficiently above $\hat{L}$ and it surpasses the historical peak in life expectancy (i.e. individuals with a high life expectancy, type a, have the evolutionary advantage and as they dominate the population life expectancy rises)

Proof. The proposition is a corollary of Proposition 2, noting A4.

Once population density is above $\hat{L}$, life expectancy is affected by two opposing forces. On the one hand, the fraction of individuals of type $a$ - the high life expectancy type - increases monotonically. On the other hand, however, the increase in population density increases the extrinsic mortality risk and thus decreases the life expectancy of the population, for any given distribution of types. Hence, since in the limit the population is dominated by the high life expectancy type, eventually the first effect dominates and life expectancy increases. This analysis is consistent with the insights derived in Proposition 1 for the case of a continuum of types.

\subsubsection{Population Dynamics Across Types}

In period 0 , the adult population consists of two types of individuals: $L_{0}^{a}$ identical adult individuals of type $a$ and $L_{0}^{b}$ identical adult individuals of type $b$, where $L_{0}^{a}+L_{0}^{b}=L_{0}<\bar{L}$. Since individuals of type $b$ are characterized by the evolutionary optimal level of somatic investment at least until period 0 , and since $\rho \rightarrow 1$, they dominate the population and $L_{0}^{b} \rightarrow L_{0}$. 
In period 0, individuals of type $a$, despite being characterized by higher life expectancy do not have the evolutionary advantage. Given the environment, the cost associated with the maintenance of higher life expectancy is not beneficial from an evolutionary viewpoint, i.e., higher life expectancy leads to a lower reproduction rate.

The population dynamics of individuals of type $i$ are determined by their fertility rates, $n_{t}^{i}$, their survival probability $P_{t}^{i}$, and the rate of transmission of the genetic type from parents to offspring, $\rho$. The distribution of types in the population, therefore, is governed by the forces of natural selection, giving an evolutionary advantage (i.e., higher expected number of surviving offspring) to the type that fits the economic environment.

The evolution of the population of individuals of types, $a$ and $b$, is therefore

$$
\begin{aligned}
& L_{t+1}^{a}=L_{t}^{a} n_{t}^{a} \rho+L_{t}^{b} n_{t}^{b}(1-\rho) ; \\
& L_{t+1}^{b}=P^{b}\left(L_{t}\right)\left[L_{t}^{b} n_{t}^{b} \rho+L_{t}^{a} n_{t}^{a}(1-\rho)\right],
\end{aligned}
$$

where

$$
L_{t+1}^{a}+L_{t+1}^{b}=L_{t+1}
$$

Let $\lambda_{t}$ be the fraction of individuals of type $a$ in the adult population in period $t$, i.e.,

$$
\lambda_{t} \equiv L_{t}^{a} / L_{t}
$$

It follows from (17) and (19) that

$$
\lambda_{t+1}=\frac{\lambda_{t} \theta \rho+\left(1-\lambda_{t}\right)(1-\rho)}{\left[\left(1-\lambda_{t}\right) \rho+\lambda_{t} \theta(1-\rho)\right] P^{b}\left(L_{t}\right)+\lambda_{t} \theta \rho+\left(1-\lambda_{t}\right)(1-\rho)} .
$$

Thus, since $\rho \rightarrow 1$, the fraction of individuals of type $a$ in the adult population in period $t+1$ is

$$
\lim _{\rho \rightarrow 1} \lambda_{t+1}=\frac{\lambda_{t} \theta}{\left(1-\lambda_{t}\right) P^{b}\left(L_{t}\right)+\lambda_{t} \theta} \equiv \phi\left(\lambda_{t}, L_{t}\right) .
$$

Lemma 3 (The Properties of $\phi\left(\lambda_{t}, L_{t}\right)$ ). Under A4, as depicted in Figure 4,

$$
\begin{array}{lll}
\phi\left(0, L_{t}\right)=0 ; \phi\left(1, L_{t}\right)=1 \quad \text { for any } & L_{t}>0 \\
\phi_{\lambda}\left(\lambda_{t}, L_{t}\right)>0 ; \phi_{L}\left(\lambda_{t}, L_{t}\right)>0 & \text { for any } & L_{t}>0 \text { and } \lambda_{t} \in[0,1],
\end{array}
$$

and there exists $\hat{L}>0$ such that $P^{b}(\hat{L})=\theta$ and

$$
\begin{aligned}
& \phi\left(\lambda_{t}, \hat{L}\right)=\lambda_{t} ; \\
& \phi_{\lambda \lambda}\left(\lambda_{t}, L_{t}\right) \lesseqgtr 0 \quad \text { if and only if } L_{t} \gtreqless \hat{L} .
\end{aligned}
$$

Proof. The Lemma follows directly from (23) noting A4. 


\subsection{The Dynamics of Population Size}

The evolution of the population size, as follows from (19), and (20), noting that $\rho \rightarrow 1$, is

$$
\lim _{\rho \rightarrow 1} L_{t+1}=\lim _{\rho \rightarrow 1}\left(L_{t+1}^{a}+L_{t+1}^{b}\right)=L_{t} \lambda_{t} n_{t}^{a}+\left(1-\lambda_{t}\right) L_{t} n_{t}^{b} P^{b}\left(L_{t}\right) .
$$

Hence, since $n_{t}^{a}=\theta n_{t}^{b}$, it follows that

$$
\lim _{\rho \rightarrow 1} L_{t+1}=L_{t} n_{t}^{b}\left[\lambda_{t} \theta+\left(1-\lambda_{t}\right) P^{b}\left(L_{t}\right)\right]
$$

and thus, noting (8) and (10),

$$
\lim _{\rho \rightarrow 1} L_{t+1}=\beta A_{t}^{\alpha} L_{t}^{1-\alpha}\left[\lambda_{t} \theta+\left(1-\lambda_{t}\right) P^{b}\left(L_{t}\right)\right] / \mu^{b} \equiv \psi\left(\lambda_{t}, L_{t} ; A_{t}\right) .
$$

In order to simplify the exposition and to assure the uniqueness of a steady-state level of population size and the monotonic convergence to this level (for a given technological level, $A_{t}$, and for a given fraction of type $a$ in the population, $\lambda_{t}$ ), it is assumed that the absolute value of the elasticity of the survival probability, $P_{t}^{b}$, with respect to $L_{t}$ is smaller than the elasticity of income with respect to labor, $1-\alpha$.

$$
\left|\frac{P^{b}\left(L_{t}\right) L_{t}}{P^{b}\left(L_{t}\right)}\right|<1-\alpha
$$

Lemma 4 (The Properties of $\left.\psi\left(\lambda_{t}, L_{t} ; A_{t}\right)\right)$. Under $A_{4}$ and A5,

$$
\begin{array}{ll}
\text { a. } & \psi_{L}\left(\lambda_{t}, L_{t} ; A_{t}\right)>0 ; \quad \psi_{L L}\left(\lambda_{t}, L_{t} ; A_{t}\right)<0 ; \\
\text { b. } & \psi_{A}\left(\lambda_{t}, L_{t} ; A_{t}\right)>0 ; \\
\text { c. } & \psi_{\lambda}\left(\lambda_{t}, L_{t} ; A_{t}\right) \gtreqless 0 \leftrightarrow L \gtreqless \hat{L} . \\
\text { d. } & \psi\left(\lambda_{t}, 0 ; A_{t}\right)=0 \\
\text { e. } & \lim _{L \rightarrow 0} \psi_{L}\left(\lambda_{t}, L_{t} ; A_{t}\right)=\infty ; \quad \lim _{L \rightarrow \infty} \psi_{L}\left(\lambda_{t}, L_{t} ; A_{t}\right)=0 ; \\
\text { f. } & \lim _{A \rightarrow 0} \psi\left(\lambda_{t}, L_{t} ; A_{t}\right)=0 ; \quad \lim _{A \rightarrow \infty} \psi\left(\lambda_{t}, L_{t} ; A_{t}\right)=\infty
\end{array}
$$

Proof. See Appendix. 


\subsection{Technological Progress}

Technological progress in the Malthusian epoch is commonly viewed (e.g., Boserup (1965), Diamond (1997)) as being driven by population size and population density. A Larger population fosters technological progress via the increase in the supply of ideas, the demand for ideas, the diffusion of ideas, the division of labor, and trade. Population size and population density, therefore, have a positive effect on technological progress. ${ }^{36}$

Suppose that technological progress, $g_{t+1}$, that takes place from periods $t$ to period $t+1$ depends upon the population size in period $t, L_{t}$.

$$
g_{t+1} \equiv \frac{A_{t+1}-A_{t}}{A_{t}}=g\left(L_{t}\right),
$$

where $g\left(L_{t}\right)>0$ and $g^{\prime}\left(L_{t}\right)>0 \quad \forall L_{t}>0$.

The level of technology at time $t+1, A_{t+1}$, is therefore

$$
A_{t+1}=\left[1+g_{t+1}\right] A_{t}=\left[1+g\left(L_{t}\right)\right] A_{t}
$$

where the technological level at time 0 is historically given at a level $A_{0}>0$.

\section{The Dynamical System}

The development of the economy is characterized by the trajectory of the size of the population, the distribution of types within the population, and the level of technology. The dynamic path of the economy is fully determined by a sequence $\left\{\lambda_{t}, L_{t}, A_{t}\right\}_{t=0}^{\infty}$ that satisfies (23), (26) and (28) in every period $t$ and describes the time path of the fraction of individuals of type $a$ in the adult population, $\lambda_{t}$, the number of adult individuals in the population, $L_{t}$, and the level of technology, $A_{t}$.

\subsection{The $\lambda \lambda$ Locus}

The $\lambda \lambda$ locus, as depicted in Figure 5 , is the geometric place of all pairs $\left(\lambda_{t}, L_{t}\right)$ such that $\lim _{\rho \rightarrow 0} \lambda_{t}$, is in a steady state. As follows from (23)

$$
\lambda \lambda \equiv\left\{\left(\lambda_{t}, L_{t}\right): \lim _{\rho \rightarrow 1}\left(\lambda_{t+1}-\lambda_{t}\right)=\frac{\lambda_{t} \theta}{\left(1-\lambda_{t}\right) P^{b}\left(L_{t}\right)+\lambda_{t} \theta}-\lambda_{t}=0\right\} .
$$

\footnotetext{
${ }^{36}$ In the modern economy, the scale of the economy may reflect a lower investment in the human capital of the population (due to a tradeoff between child quality and quantity) and may thus have an ambiguous effect of technological progress.
} 
Hence,

$$
\begin{aligned}
& \lim _{\rho \rightarrow 1}\left(\lambda_{t+1}-\lambda_{t}\right)=0 \quad \text { if } \quad\left\{\begin{array}{l}
\lambda_{t}=0 \\
\lambda_{t}=1
\end{array} \forall L_{t}\right. \\
& \lim _{\rho \rightarrow 1}\left(\lambda_{t+1}-\lambda_{t}\right) \gtreqless 0 \quad \text { if } \quad L_{t} \gtreqless \hat{L} \quad \forall \lambda_{t} \in(0,1),
\end{aligned}
$$

where $L_{t} \gtreqless \hat{L}$ if and only if $P^{b}\left(L_{t}\right) \lesseqgtr \theta$.

Hence the fraction of individuals of type $a$ in the population, $\lambda_{t}$, is in a steady state if:

(a) $\lambda_{t}=0$, i.e.,, if there are no individuals of type $a$ in the population in period $t$ and thus there will be no individuals of type $a$ in all future periods

(b) $\lambda_{t}=1$, i.e., if there are only individuals of type a in the population and thus there will be only individuals of type $a$ in all future periods.

(c) For any $\lambda_{t}, L_{t}=\hat{L}$, i.e., none of the two types have an evolutionary advantage and thus there are no changes in the composition of the population over time.

Furthermore, for any $\lambda_{t} \in(0,1)$, if $L_{t}<\hat{L}$ and thus $\lambda_{t}$ is not in a steady state then $\lim _{\rho \rightarrow 1}\left(\lambda_{t+1}-\lambda_{t}\right)<0$ and the fraction of individuals of type $a$ decreases, whereas if $L_{t}>\hat{L}$ then $\lim _{\rho \rightarrow 1}\left(\lambda_{t+1}-\lambda_{t}\right)>0$ and the fraction of individuals of type $a$ increases.

\subsection{The $L L$ Locus}

The $L L$ locus, as depicted in Figure 5, is the geometric place of all pairs $\left(\lambda_{t}, L_{t}\right)$ such that, for a given $A_{t}$, the population size, $L_{t}$, is in a steady state.

$$
L L \equiv\left\{\left(\lambda_{t}, L_{t} ; A_{t}\right): L_{t+1}-L_{t}=\psi\left(\lambda_{t}, L_{t} ; A_{t}\right)-L_{t}=0\right\}
$$

Lemma 5 (The properties of the LL Locus).

Under A4 and A5, along the LL locus

$$
L_{t}=L^{L L}\left(\lambda_{t} ; A_{t}\right)>0,
$$

and there exists a unique $A_{t}=\hat{A}>0$ such that for all $\lambda_{t}$

$$
\begin{gathered}
L^{L L}\left(\lambda_{t} ; A_{t}\right)\left\{\begin{array}{lll}
<\hat{L} & \text { for } & A_{t}<\hat{A} \\
=\hat{L} & \text { for } & A_{t}=\hat{A} \\
>\hat{L} & \text { for } & A_{t}>\hat{A}
\end{array}\right. \\
\frac{d L^{L L}\left(\lambda_{t} ; A_{t}\right)}{d \lambda_{t}}=\frac{\psi_{\lambda}\left(\lambda_{t}, L_{t} ; A_{t}\right)}{1-\psi_{L}\left(\lambda_{t}, L_{t} ; A_{t}\right)}\left\{\begin{array}{lll}
<0 & \text { for } & A_{t}<\hat{A} \\
=0 & \text { for } & A_{t}=\hat{A} \\
>0 & \text { for } & A_{t}>\hat{A}
\end{array}\right.
\end{gathered}
$$




$$
d L^{L L}\left(\lambda_{t} ; A_{t}\right) / d A_{t}>0
$$

Proof. As follows from Lemma 4, there exists a unique steady state level of $L_{t}$ for any pair $\left(\lambda_{t} A_{t}\right)$. Hence, $L_{t}=L^{L L}\left(\lambda_{t} ; A_{t}\right)$. As follows from (26), there exist a unique $A_{t}=\hat{A}>0$ such that $L^{L L}\left(\lambda_{t} ; A_{t}\right)=\hat{L}$ (where the independence of $\hat{A}$ in $\lambda_{t}$ follows from the fact that $\left.P^{b}(\hat{L})=\theta\right)$. Furthermore, the remaining properties follow immediately from simple manipulations of (26), noting that as follows from the properties (a),(b), and (e) of the function $\psi\left(\lambda_{t}, L_{t} ; A_{t}\right)$ stated in Lemma 4 , at the conditional steady-state level of $L_{t}, \psi_{L}\left(\lambda_{t}, L^{L L}\left(\lambda_{t} ; A_{t}\right) ; A_{t}\right)<1$.

Corollary 1 For all $\lambda_{t}$ and $A_{t}$,

$$
L_{t+1}-L_{t} \gtreqless 0 \quad \text { if and only if } L_{t} \lesseqgtr L^{L L}\left(\lambda_{t} ; A_{t}\right) \text {. }
$$

\subsection{The Evolution of Life Expectancy along the Process of Development}

This section describes the evolution of the composition of types and life expectancy from period 0 to a long-run steady-state equilibrium.

Suppose that in this early stage of development the level of technology is rather low (i.e.,

$A_{0}<\hat{A}$ ) and the economy can sustain a small population, $L_{t}<\bar{L}<\hat{L}$. Hence, $P^{b}\left(L_{t}\right)>\theta$, and therefore individuals of type $b$ have an evolutionary advantage, and as depicted in Figures $2 \mathrm{a}$ and $3 \mathrm{a}$, the fraction of individuals of type $a$ in the population, is nearly zero, i.e., $\lambda_{t} \rightarrow 0$. 
Furthermore, since $P^{b}\left(L_{t}\right)=0$ for $L_{t}<\bar{L}$, life expectancy is nearly constant.

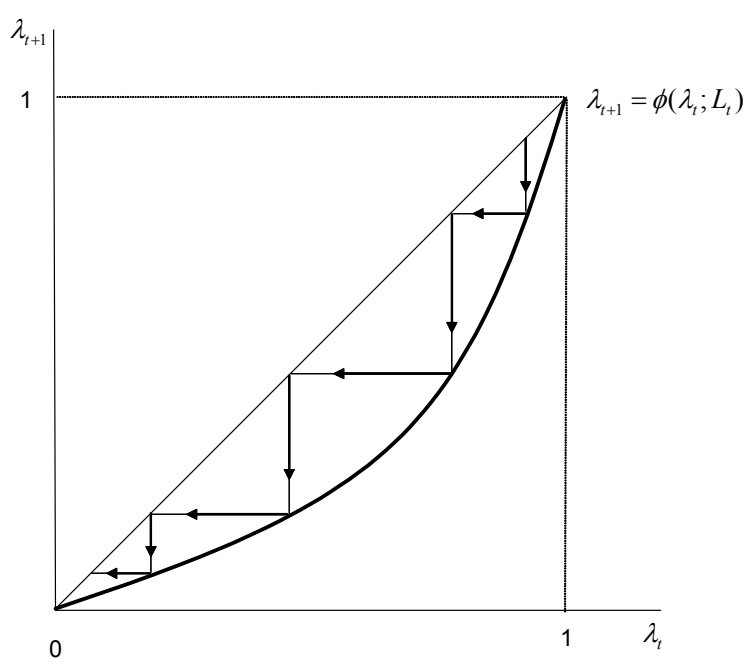

(a) $\quad \hat{L}>L_{t}$

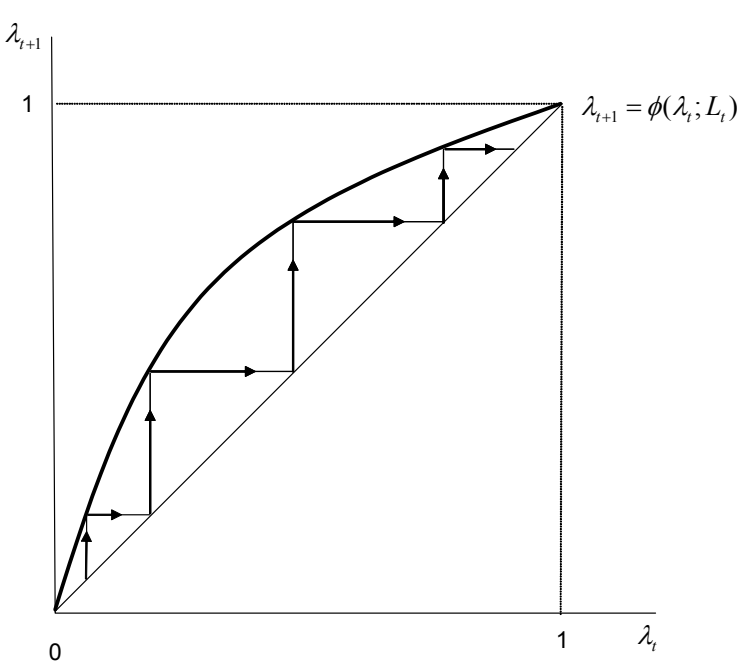

(b) $\hat{L}<L_{t}$

Figure 4. The evolution of the fraction of individuals of type $a$ in the population for a given level of population density below (panel $(a)$ ) above (panel $(b)$ ) the threshold for which type $a$ gains the evolutionary advantage.

Hence, in early stages of development, the environment is characterized by low population density, and individuals that are characterized by low somatic investment and thus low life expectancy have an evolutionary advantage. They dominate the population and their life expectancy becomes the life expectancy of the population as a whole. Since extrinsic mortality over this period remains constant, life expectancy remains constant as well.

As $A_{t}$ increases over time, the size of the population increases and the $L L$ locus, depicted in Figure 4a, shifts upward, but remains below $\hat{L}$ as long as $A_{t}<\hat{A}$. As the population, $L_{t}$, increases gradually and exceeds $\bar{L}$ it generates an increase in mortality rates among type $b$ individuals, decreasing the downward curvature of $\phi\left(\lambda_{t}, L_{t}\right)$, depicted in Figure 4a. However, the structure of $\lambda_{t+1}=\phi\left(\lambda_{t}, L_{t}\right)$ remains convex with respect to $\lambda_{t}$. Thus, $\lambda_{t}=0$ is the stable conditional steady state and the evolutionary advantage remains among individuals of type $b$.

Hence, as population density increases over time, increasing moderately the extrinsic mortality risk, individuals that are characterized by low somatic investment and thus low life expectancy still maintain their evolutionary advantage. They continue to dominate the population and their life expectancy is the life expectancy of the population as a whole. However since extrinsic mortality increases moderately over this period, life expectancy declines. 
As $A_{t}$ continue to increase over time, the size of the population increases and the $L L$ locus, depicted in Figure 5, continues to shift upward. Ultimately $A_{t}$ passes the threshold $\hat{A}$, triggering a qualitative change in the dynamical system. The level of technology $A_{t}>\hat{A}$ sustains a population of a size larger than the population threshold $\hat{L}$, and individuals of type $a$ gain the evolutionary advantage. The qualitative change in the process of evolution is reflected by the qualitative change in the structure of $\phi\left(\lambda_{t} ; L_{t}\right)$. As depicted in Figure $4, \phi\left(\lambda_{t} ; L_{t}\right)$ turns from a convex function of $\lambda_{t}$, in Figure $4 a$, to a concave function of $\lambda_{t}$ in Figure $4 b$, implying that the globally stable fraction of individuals of type $a$ is 1 , rather then 0 . Hence, as depicted in Figures $3 b$ and $3 b$, the fraction of type $a$ individuals in the economy, $\lambda_{t}$, increases over time and converges to 1.

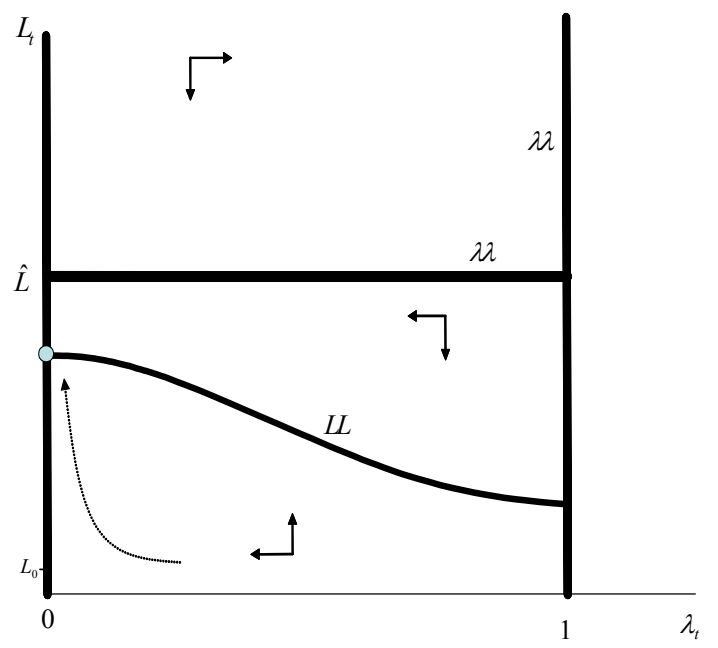

(a) $\hat{A}>A_{t}$

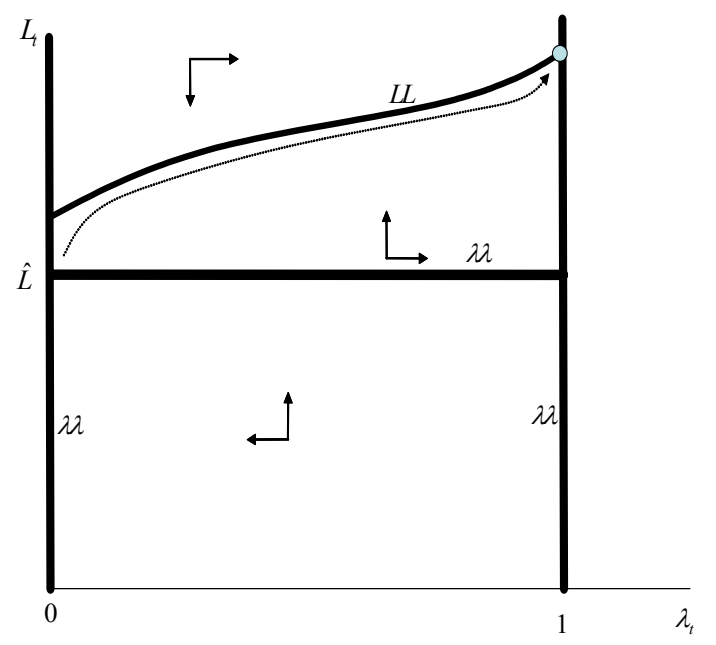

(b) $\hat{A}<A_{t}$

Figure 5. The evolution of the fraction of individuals of type $a$ in the population for a given level of population density for a given level a technology - above (panel $(a)$ ) and below (panel $(b))$ the population density threshold above which generates an evolutionary.

Once population density is above $\hat{L}$, life expectancy is affected by two opposing forces. On the one hand, the fraction of individuals with the high life expectancy, type $a$, increases monotonically. On the other hand, however, the increase in population density increases the extrinsic mortality risk and thus decreases the life expectancy of the population, for any given distribution of types as long as the fraction of individuals of type $b$ in the population remains significant. Hence, since in the limit the population is dominated by the high life expectancy type, eventually the first effect dominates and life expectancy increases.

Hence, as population density increases over time, increasing the extrinsic mortality risk, 
individuals that are characterized by high somatic investment and thus high life expectancy gain the evolutionary advantage. They gradually dominate the population and in the long run their life expectancy becomes the life expectancy of the population as a whole. However since the extrinsic mortality risk increases over this period, life expectancy may further decline prior to a gradual increase to a long run level that is beyond its peak in early stages of development. 


\section{Concluding Remarks}

This research develops a theory about the evolution of life expectancy in the process of development. The theory argues that social, economic and environmental changes that were associated with the transition from hunter-gatherer tribes to sedentary agricultural communities and ultimately to urban societies affected the nature of the environmental hazards confronted by the human population, triggering an evolutionary process that had a significant impact on the time path of human longevity. The increase in the extrinsic morality risk (i.e., risk associated with environment factors) associated with the Agricultural Revolution triggered an evolutionary pro-

cess, further enhanced by the process of urbanization, that gradually altered the distribution of genes in the human population that are associated with the intrinsic mortality risk (i.e., physiological and biochemistry decay over lifetime). Individuals that were characterized by a higher genetic pre-disposition towards somatic investment, repairs, and maintenance (e.g., enhanced immune system, DNA repairs, accurate gene regulation, tumor suppression, and antioxidants) gained the evolutionary advantage during this transition, and their representation in the population increased over time. Despite the increase in the extrinsic mortality risk that brought about a temporary decline in life expectancy, longevity eventually increased beyond the peak that existed in the hunter-gatherer society, due to the changes in the distribution of genes in the human population. Moreover, the biological upper bound of longevity increased, generating the biological infrastructure for the recent prolongation of life expectancy that was brought about by the decline in the extrinsic mortality risk due to improvements in medical technology. 


\section{Appendix 1}

\section{Proof of Proposition 1:}

As follows from (12), the negativity of $P_{x}\left(\mu^{*}, x_{t}\right)$ and $P_{\mu \mu}\left(\mu^{i}, x_{t}\right)$, and Assumptions A1 and A2,

$$
\mu^{* \prime}\left(x_{t}\right)=-\frac{P_{\mu x}\left(\mu^{*}, x_{t}\right) \mu^{*}-P_{x}\left(\mu^{*}, x_{t}\right)}{P_{\mu \mu}\left(\mu^{*}, x_{t}\right) \mu^{*}}>0 .
$$

Furthermore, as follows from (32), the negativity of $P_{x}\left(\mu^{*}, x_{t}\right)$, the positivity of $P_{\mu}\left(\mu^{i}, x_{t}\right)$, and Assumptions A1-A3,

$$
\frac{d P\left(\mu^{*}\left(x_{t}\right), x_{t}\right)}{d x}=P_{\mu}\left(\mu^{i}, x_{t}\right) \mu^{* \prime}\left(x_{t}\right)+P_{x}\left(\mu^{i}, x_{t}\right)>0 .
$$

Using (32)

$$
\frac{d p\left(\mu^{i}\left(x_{t}\right), x_{t}\right)}{d L}=-P_{\mu^{i}}\left(\mu^{i}, x_{t}\right) \frac{P_{\mu x}\left(\mu^{i}, x_{t}\right) \mu^{i}-P_{x}\left(\mu^{i}, x_{t}\right)}{P_{\mu \mu}\left(\mu^{i}, x_{t}\right) \mu^{i}}+P_{x}\left(\mu^{i}, x_{t}\right) .
$$

Hence,

$$
\frac{d P\left(\mu^{*}\left(x_{t}\right), x_{t}\right)}{d x}>0 \quad \text { iff } \quad P_{\mu^{i}}\left(\mu^{i}, x_{t}\right) P_{\mu x}\left(\mu^{i}, x_{t}\right) \mu^{i}>P_{x}\left(\mu^{i}, x_{t}\right)\left[P_{\mu \mu}\left(\mu^{i}, x_{t}\right) \mu^{i}+P_{\mu^{i}}\left(\mu^{i}, x_{t}\right)\right],
$$

and thus

$$
\frac{d E\left(P\left(\mu^{*}\left(x_{t}\right), x_{t}\right)\right)}{d x}>0 \quad \text { if } \quad P_{\mu^{i}}\left(\mu^{i}, x_{t}\right) / \mu^{i}>\left|P_{\mu \mu}\left(\mu^{i}, x_{t}\right)\right| .
$$

Finally, since $\mu^{* \prime}\left(x_{t}\right)>0$ and $P_{\mu}\left(\mu^{i}, x_{t}\right)>0$,

$$
\frac{d E\left(P\left(\mu^{*}\left(x_{t}\right), 0\right)\right)}{d x}>0 .
$$

\section{Proof of Lemma 4.}

(a) As follows from (26), noting that as follows from A5, $(1-\alpha) P^{b}\left(L_{t}\right)+P^{b},\left(L_{t}\right) L_{t}>0$,

$$
\begin{aligned}
\psi_{L}\left(\lambda_{t}, L_{t} ; A_{t}\right)= & \left(\beta / \mu^{b}\right) A_{t}^{\alpha} L_{t}^{-\alpha}\left[(1-\alpha) \lambda_{t} \theta+\left(1-\lambda_{t}\right)\left[(1-\alpha) P^{b}\left(L_{t}\right)+P^{b} \prime\left(L_{t}\right) L_{t}\right]\right]>0 \\
\psi_{L L}\left(\lambda_{t}, L_{t} ; A_{t}\right)= & \\
& -\alpha\left(\beta / \mu^{b}\right) A_{t}^{\alpha} L_{t}^{-(1+\alpha)}\left[(1-\alpha) \lambda_{t} \theta+\left(1-\lambda_{t}\right)\left[(1-\alpha) P^{b}\left(L_{t}\right)+P^{b} \prime\left(L_{t}\right) L_{t}\right]\right] \\
& +\left(\beta / \mu^{b}\right) A_{t}^{\alpha} L_{t}^{-\alpha}\left(1-\lambda_{t}\right)\left[(2-\alpha) P^{b} \prime\left(L_{t}\right)+P^{b} \prime\left(L_{t}\right) L_{t}\right]<0
\end{aligned}
$$

(b) Follows directly from $\psi\left(\lambda_{t}, L_{t} ; A_{t}\right)$.

(c) Follows from $\psi\left(\lambda_{t}, L_{t} ; A_{t}\right)$ noting that $\psi_{\lambda}\left(\lambda_{t}, L_{t} ; A_{t}\right)=\left(\beta / \mu^{b}\right) A_{t}^{\alpha} L_{t}^{1-\alpha}\left[\theta-P^{b}\left(L_{t}\right)\right]$. 
(d) Follows directly from (26).

(e) Since, $\left.\psi_{L \lambda}\left(\lambda_{t}, L_{t} ; A_{t}\right)=\left(\beta / \mu^{b}\right) A_{t}^{\alpha} L_{t}^{-\alpha}\left[(1-\alpha)\left[\theta-P^{b}\left(L_{t}\right)\right]-P^{b}\left(L_{t}\right) L_{t}\right]\right]>0$ for $L>\hat{L}$, it follows that, for $L_{t}>\hat{L}, \psi_{L}\left(1, L_{t} ; A_{t}\right) \geq \psi_{L}\left(\lambda_{t}, L_{t} ; A_{t}\right)$ for all $\lambda_{t}$, and therefore, since $\psi_{L}\left(\lambda_{t}, L_{t} ; A_{t}\right)>0$

$$
\lim _{L \rightarrow \infty} \psi_{L}\left(\lambda_{t}, L_{t} ; A_{t}\right) \leq \lim _{L \rightarrow \infty} \psi_{L}\left(1, L_{t} ; A_{t}\right)=0
$$

(f) Follows directly from the structure of $\psi\left(\lambda_{t}, L_{t} ; A_{t}\right)$. 


\section{Appendix 2}

Table 1. Life Expectancy: From the Epipalaeolithic Period to the Iron Age

\begin{tabular}{|c|c|c|c|c|c|}
\hline Period & Place & $\begin{array}{l}\text { Dates } \\
\text { (B.C.E) }\end{array}$ & & $\begin{array}{c}\text { Life } \\
\text { Expectancy }\end{array}$ & \\
\hline & & & at age 0 & at age 15 & $\begin{array}{c}\text { at age } \\
20\end{array}$ \\
\hline \multirow[t]{7}{*}{$\begin{array}{l}\text { Epipalaeolithic } \\
\text { Mesolithic1 }\end{array}$} & & $17000-7000$ & & & \\
\hline & $\begin{array}{l}\text { Taforalt Cave } \\
\text { (Morocco) }\end{array}$ & & 21.4 & 26.9 & 23.9 \\
\hline & $\begin{array}{l}\text { A falou-Bou-Rommel } \\
\text { (Algeria) }\end{array}$ & & & & 21.9 \\
\hline & Vassilievka (USSR) & & 39.88 & & 22.8 \\
\hline & Hayonim Cave (Israel) & & 23.57 & 14.7 & 11.94 \\
\hline & Sahaba (Nile Valley) & & 34.45 & 25.6 & 21.6 \\
\hline & Maghreb Type Model & & 21.145 & 27.783 & 24.521 \\
\hline \multicolumn{6}{|l|}{ Neolithic ${ }^{1}$} \\
\hline & Catal Huyuk & $7000-6000$ & & 16.9 & \\
\hline & Vovnigi (Russia) & 4000 & & & 21 \\
\hline & Khirokitia (Cyprus) & $4000-3000$ & 22.1 & 19.4 & 14.7 \\
\hline & Khirokitia (Cyprus) & $4000-3000$ & 17 & & 16 \\
\hline & Volni (Ukraine) $^{2}$ & $3500-2500$ & 24.92 & 19.81 & 16.25 \\
\hline \multicolumn{6}{|l|}{ Copper Age } \\
\hline & $\begin{array}{l}\text { Tiszapolgar-Basatanya } \\
\text { (Hungary) }\end{array}$ & $3500-2000$ & 36.37 & 28.44 & 26.46 \\
\hline & Alsonemedi (Hungary) & $2100-1900$ & 28.86 & 28.44 & 25.66 \\
\hline \multicolumn{6}{|l|}{ Bronze Age ${ }^{2}$} \\
\hline & Mezocsat & $1400-1200$ & 28.97 & 24.72 & 22.81 \\
\hline \multicolumn{6}{|l|}{ Iron $\mathbf{A g e}^{2}$} \\
\hline & Mezocsat & $800-700$ & 44.03 & 34.5 & 31.67 \\
\hline
\end{tabular}

[1] Fekri (1981, Chapter 7 pp. 95-128)

[2] Acsadiand and Nemeskeri (1970, pp. 273-287) 


\section{References}

[1] Acsa'di, G.Y., and J. Nemeskeri, (1970), History of Human Life Span and Mortality, (Akademiai Kiado, Budapest).

[2] Angel, L. J., (1984), "Health as a Crucial Factor in the Changes from Hunting to Developed Farming in the Eastern Mediterranean." in Cohen M.N. and Armelagos G.J. (eds.), Paleopathology at the Origins of Agriculture, (Florida: Academic Press Inc.).

[3] Bairoch, P. (1988), Cities and Economic Development (The University of Chicago Press, Chicago).

[4] Becker, G. (1976), "Altruism, Egoism and Genetic Fitness: Economics andSociobiology", Journal of Economic Literature, 14, 817-826

[5] Bisin, A., and T. Verdier (2000), "Beyond the Melting Pot: Cultural Transmission, Marriage, and the Evolution of Ethnic and Religious Traits", Quarterly Journal of Economics 115: 955-988.

[6] Borghans, J.A.M., L. Borghans and B. ter-Weel, (2004), "Economic Performance,Human Cooperation,and the Major Histocompatibility Complex," Maastricht.

[7] Boserup, E., (1965). The Conditions of Agricultural Progress, (Aldine Publishing Company, Chicago).

[8] Boucekkine, R, D. de la Croix and O. Licandro.(2003), "Early Mortality Declines at the Dawn of Modern Growth," Scandinavian Journal of Economics, 105: 401-418.

[9] Bowles, S. (1998), "Endogenous Preferences: The Cultural Consequences of Markets and other Economic Institutions," Journal of Economic Literature 36: 75-111.

[10] Boyd, R., and P.J. Richardson (1985), Culture and the Evolutionary Process (University of Chicago Press, Chicago).

[11] Boyer, G. (1989), "Malthus was Right After All: Poor Relief and Birth Rates in SouthEastern England", Journal of Political Economy 97: 93-114.

[12] Cavalli-Sforza, L.L., and M.W. Feldman (1981), Cultural Transmission and Evolution: A Quantitative Approach (Princeton University Press, Princeton). 
[13] Cervellati, M. and U. Sunde (2003), "Human Capital Formation,Life Expectancy and the Process of Development," Iza.

[14] Clark, G. and G. Hamilton (2003) "Survival of the Fittest? Capital, Human Capital, and Reproduction in European Society before the Industrial Revolution" UC Davis.

[15] Cody, M. L. (1966), “A General Theory of Clutch Size,” Evolution, 20 174-184.

[16] Cohen M. N.,(1989), Health and the Rise of Civilization (Yale Uni. Press: New Haven).

[17] Dawkins, R. (1989), The Selfish Gene (Oxford University Press, Oxford).

[18] De Vries, J. (1984). European Urbanization, 1500-1800 (Harvard University Press, Cambridge).

[19] Diamond, J. (1997),.Guns, Germs, and Steel: The Fates of Human Societies.(Norton, New York).

[20] Durham, W. (1982), "Interaction of Genetic and Cultural Evolution: Models and Examples", Human Ecology 10: 289-323.

[21] Endler, J.A. (1986), Natural Selection in the Wild (Princeton University Press, Princeton).

[22] Erlich, I., and F. T. Lui (1991), "Intergenerational trade, Longevity, and Economic Growth," Journal of Political Economy 99: 1029-1059.

[23] Fekri, A. H., (1981), Demographic Archaeology, (Academic Press: New York).

[24] Fogel, R. W.(1994), "Economic Growth, Population Theory, and Physiology: The Bearing of Long-Term Processes on the Making of Economic Policy." American Economic Review 84: 369-95.

[25] Galor, O., and O. Moav (2002), "Natural Selection and the Origin of Economic Growth", Quarterly Journal of Economics 117: 1133-1192.

[26] Galor, O., and D.N. Weil (1999), "From Malthusian Stagnation to Modern Growth", American Economic Review, 89: 150-154.

[27] Grant, B.R., and P.R. Grant (1989), Evolutionary Dynamics of a Natural Population (University of Chicago Press, Chicago). 
[28] Hansson, I., and C. Stuart (1990), "Malthusian Selection of Preferences", American Economic Review 80: 529-544.

[29] Hazan, M. and H. Zoabi (2004). "Longevity, Fertility and Economic Growth," Hebrew University.

[30] Iyigun, M. F. (2005), "Geography, Demography, and Early Development," Journal of Population Economics (forthcoming).

[31] Jones, E.L. (1981), The European Miracle: Environments, Economies and Geopolitics in the History of Europe and Asia (Cambridge University Press, Cambridge).

[32] Kalemli-Ozcan, S., H.E. Ryder and D. N. Weil (2000), "Mortality Decline,Human Capital Investment,and Economic Growth" Journal of Development Economics, 62: 1-23

[33] Kettlewell, H.B.D. (1973), The Evolution of Melanism (Clarendon Press, Oxford).

[34] Kirkwood T.B.L. (1998), Evolution Theory and the Mechanisms of Aging. In: Textbook of Geriatric Medicine, 5th ed. (Brocklehurst JC, Tallis RC, eds). London: Churchill Livingstone, pp45-49.

[35] Kirkwood T.B.L and F.R.S. Holliday (1979) "The evolution of ageing and longevity", Proceedings of the Royal Society of London B 205: 531-546.

[36] Kohler, H., J.L. Rodgers and K. Christensen (1999), "Is Fertility Behavior in our Genes? Findings from a Danish Twin Study", Population and Development Review 25: 253-263.

[37] Lack, D., (1954), The Natural Regulation of Animal Numbers (Oxford: Clarendon Press).

[38] Lagerlof, N., (2003), "From Malthus to Modern Growth: The Three Regimes Revisited", International Economic Review 44: 755-777.

[39] Lagerlof, N.P. (2004), "From Arnold Schwarzenegger to Woody Allen: Long-Run Trends in Human Body Size," York University.

[40] Laxton, P. and N. Williams (1989) "Urbanization and Infant Mortality in England", in M.C. Nelson and J. Rogers, eds. Urbanization and the Epidemiological Transition Uppsala University. 
[41] Livi-Bacci, M. (1997), A Concise History of World Population (Blackwel, Oxford).

[42] Livingston F, (1958), "Anthropological Implications of Sickle Cell Distribution in West Africa", American Anthropologist 60: 533-562.

[43] Malthus, T.R. (1798), An Essay on the Principle of Population (printed for J. Johnson, in St. Paul's Church-Yard, London).

[44] McNeil, W.H., 1998, Plagues and Peoples, Anchor press, Doublebay.

[45] Medawar, P.B. (1952) An Unsolved Problem of Biology H.K. Lewis \& Co. London

[46] Mokyr, Joel.(1998), "Induced Technical Innovation and Medical History: An Evolutionary Approach." Journal of Evolutionary Economics, 8: 119-137.

[47] Ofek, Haim, (2001), Second Nature: Economic origin of Human evolution. Cambridge: Cambridge University Press.

[48] Robson, A.J. (2002) "Evolution and Human Nature," Journal of Economic Perspectives 16 , 89-106.

[49] Robson A. J. and H. S. Kaplan (2003), "The Evolution of Human Longevity and Intelligence in Hunter-Gatherer Economies," American Economic Review 93: 150-169.

[50] Rodgers, J.L., and D. Doughty (2000), "Genetic and Environmental Influences on Fertility Expectations and Outcomes Using NLSY Kinship Data", in: J.L. Rodgers, D.C. Rowe and W.B. Miller, eds., Genetic Influences on Human Fertility and Sexuality (Kluwer, Boston).

[51] Rodgers, J.L., K. Hughes, H. Kohler, K. Christensen, D. Doughty, D.C. Rowe and W.B. Miller (2001a), "Genetic influence helps explain variation in human fertility: Evidence from recent behavioral and molecular genetic studies", Current Directions in Psychological Science 10: 184-188.

[52] Rodgers, J.L., H. Kohler, K. Ohm Kyvik, and K. Christensen (2001b), "Behavior Genetic Modeling of Human Fertility: Findings from a Contemporary Danish Twin Study", Demography 38: 29-42.

[53] Saint-Paul, G. (2003), "On Market and Human Evolution” CEPR Discussion Paper No. 3654. 
[54] Soares, R. R. (2003), "Mortality Reductions, Educational Attainment,and Fertility Choice," University of Maryland.

[55] Stearns, Stephen C. (1992), The Evolution of Life Histories, Oxford: Oxford University Press.

[56] Weisdorf, J. L. (2004) "From Stagnation to Growth: Revisiting Three Historical Regimes." Journal of Population Economics (forthcoming).

[57] Weismann, A. (1882) Uber die Dauer des Lebens, Gustav Fischer, Jena, Germany.

[58] Weisenfeld, S.L. (1967), "Sickle Cell Trait in Human Biological and Cultural Evolution", Science 157: 1135-1140.

[59] Westendorp, R.G.J., Kirkwood, T.B.L. (1998), "Human Longevity at the Cost of Reproductive Success," Nature, 396: 743-746.

[60] Williams, G. (1957) "Pleiotropy, Natural Selection and the Evolution of Senescence" Evolution 11, 398-411

[61] Williams P. D. and T. Day (2003) “Antagonistic Pleiotropy, Mortality Source Interactions, And The Evolutionary Theory Of Senescence" Evolution, 57, 1478-1488.

[62] Wilson, E.O. (1975), Sociobiology: The New Synthesis, Cambridge, Mass.:Harvard University Press

[63] Wrigley, E.A., and R.S. Schofield (1981), The Population History of England 1541-1871: A Reconstruction (Harvard University Press, Cambridge). 